\title{
Wogonoside inhibits IL-1 $\beta$ induced catabolism and hypertrophy in mouse chondrocyte and ameliorates murine osteoarthritis
}

\author{
Qian Tang ${ }^{1,2}$, Gang Zheng ${ }^{1,2}$, Zhenhua Feng ${ }^{1,2}$, Minji Tong ${ }^{1,2}$, Jianxiang $X \mathbf{u}^{1,2}$, Zhiyan \\ $\mathrm{Hu}^{4}$, Ping Shang ${ }^{3}$, Yu Chen ${ }^{1}$, Chenggui Wang ${ }^{1,2}$, Yiting Lou ${ }^{1,2}$, Deheng Chen ${ }^{1,2}$, Di \\ Zhang $^{1,2}$, Majid Nisar ${ }^{1,2}$, Xiaolei Zhang ${ }^{1,2}$, Huazi Xu ${ }^{1,2}$ and Haixiao Liu ${ }^{1,2}$ \\ ${ }^{1}$ Department of Orthopaedic Surgery, The Second Affiliated Hospital and Yuying Children's Hospital of Wenzhou Medical \\ University, 325027 Wenzhou, China \\ ${ }^{2}$ Zhejiang Provincial Key Laboratory of Orthopaedics, 325027 Wenzhou, China \\ ${ }^{3}$ Department of Rehabilitation, The Second Affiliated Hospital and Yuying Children's Hospital of Wenzhou Medical University, \\ 325027 Wenzhou, China \\ ${ }^{4}$ Department of Anesthesiology, The Second Affiliated Hospital and Yuying Children's Hospital of Wenzhou Medical University, \\ 325027 Wenzhou, China \\ Correspondence to: Haixiao Liv, email: spineliv@163.com \\ Huazi Xu, email: spinexu@163.com \\ Xiaolei Zhang, email: callmeroger@126.com
}

Keywords: wogonoside, osteoarthritis, NF- $\kappa B, H I F-2 \alpha$, hypertrophy

Received: January 25, $2017 \quad$ Accepted: April 27, $2017 \quad$ Published: June 06, 2017

Copyright: Tang et al. This is an open-access article distributed under the terms of the Creative Commons Attribution License 3.0 (CC BY 3.0), which permits unrestricted use, distribution, and reproduction in any medium, provided the original author and source are credited.

\section{ABSTRACT}

The inflammatory environment is correlated with extracellular matrix (ECM) degradation and chondrocyte hypertrophy in the development of osteoarthritis (OA). Previous studies have reported the anti-inflammatory effects of wogonoside in several diseases. In the present study, we investigated the protective effects of wogonoside in relation to the development of $\mathrm{OA}$ and delineated the potential mechanism. In vitro, wogonoside decreased the production of pro-inflammatory cytokines like Nitric oxide (NO), prostaglandin E2 ( $\mathrm{PGE}_{2}$ ), tumor necrosis factor alpha (TNF- $\alpha$ ), and interleukin-6 (IL-6). It also inhibited the expression of cyclooxygenase-2 (COX-2) and inducible nitric oxide synthase (iNOS) both at gene and protein levels. Wogonoside also inhibited hypertrophy and the generation of vascular endothelial growth factor (VEGF) in interleukin-1 $\beta$ (IL-1 $\beta$ )-induced chondrocytes. Moreover, wogonoside promoted the expression of anabolic factors Sox-9, type two collagen and aggrecan while inhibiting the expression of catabolic factors such as matrix metalloproteinases (MMPs) and thrombospondin motifs 5 (ADAMTS-5) in mouse chondrocytes. Mechanistically, we found that wogonoside inhibited nuclear factor kappa B/ hypoxia-inducible factor two alpha (NF-KB/HIF-2 $\alpha$ ) activation via the phosphatidylinositol 3 kinase (PI3K) / AKT pathway. The protective effects of wogonoside were also observed in vivo and the pharmacokinetic results of wogonoside indicated that good systemic exposure was achievable after oral administration of wogonoside. In conclusion, our stduy demonstrates that wogonoside attenuates IL-1 $\beta$-induced ECM degradation and hypertrophy in mouse chondrocytes via suppressing the activation of NF-KB/HIF-2 $\alpha$ by the PI3K/AKT pathway. Moreover, wogonoside ameliorates OA progression in vivo, indicating that wogonoside may serve as a promising therapeutic agent for the treatment of $O A$. 


\section{INTRODUCTION}

Osteoarthritis (OA), a painful degenerative joint disease characterized by articular cartilage loss, subchondral bone remodeling and inflammation of the synovium, causes progressive disabilities in the elderly due to its irreversible outcomes $[1,2]$. Until now, the pathogenesis of OA is unclear and no effective therapeutic agent exists for OA [1]. However, it is generally accepted that the chondrocyte, the only cell type in articular cartilage, is a target of many potential risk factors of OA, including mechanical stress, senescence and inflammatory factors [3-5].

The extracellular matrix (ECM) mainly consists of type II collagen and aggrecan, the major components of normal cartilage that allow articular cartilage to adjust to biomechanical forces during joint movement [6]. The ECM is secreted and maintained by chondrocytes and is regulated by the Sox-9 gene, a key transcription factor for ECM homeostasis [7, 8]. There is now a general consensus that inflammation plays an important role in the OA process, contributing to the shift of chondrocyte phenotype and degradation of the ECM [8-10]. Inflammatory cytokines such as interleukin-1 beta (IL-1 $\beta$ ), interleukin-6 and tumor necrosis factoralpha (TNF- $\alpha$ ) produced by activated synoviocytes, mononuclear cells or by articular cartilage itself are strongly related to the pathophysiology of osteoarthritis [11]. Among these cytokines, the IL- $1 \beta$ exert its inflammatory effects by significantly increasing the secretion of pro-inflammatory factors and catabolic factors such as prostaglandin E2 ( $\left.\mathrm{PGE}_{2}\right)$, nitric oxide (NO), thrombospondin motifs (ADAMTS), and matrix metalloproteinases (MMPs) to destroy the ECM [1214]. In contrast, the IL-1 $\beta$ stimulus can also lead to the hypertrophic-like conversion of chondrocytes [8]. As a result, OA chondrocytes are unable to sustain cartilage homeostasis and fail to replace components of the ECM, particularly collagen.

The transcription factor nuclear factor kappa $\mathrm{B}(\mathrm{NF}-\mathrm{\kappa B})$ is a key regulator of the production of pro-inflammatory factors and catabolic factors [15]. Activation of the NF- $\mathrm{kB}$ pathway includes the phosphorylation of p 65 and I $\mathrm{I} B \alpha$ in the cytoplasm and ultimately transfer $\mathrm{p} 65$ from the cytoplasm entering the nucleus [16]. The PI3K/AKT pathway is one of most widely studied upstream signaling pathways of NF- $\kappa B$ and is a significant target of chondrocyte inflammation and apoptosis [17]. Moreover, hypoxia-inducible factor two alpha (HIF-2 $\alpha$ ), one of major angiogenic and hypertrophic factors in OA chondrocytes, is induced by well-known mediators such as IL-1 $\beta$ and TNF- $\alpha$, which directly target various catabolic factors including collagen X, ADAMTS-5, MMPs, and vascular endothelial growth factor (VEGF) to trigger cartilage destruction [18-21]. Additionally, it is worth noting that the HIF-2 $\alpha$-mediated destructive effects of chondrocytes can be initiated by NF-KB activation [19-21], suggesting a possible therapeutic target to unite anti-inflammation, anti-hypertrophy and anti-catabolism of the ECM to treat degenerative cartilage.

Currently, there are no effective target drugs for the treatment of OA [22]. Therefore, a safer and more effective drug is urgently needed to treat OA. Wogonoside, an individual component extracted from Scutellaria baicalensis Georgi, exhibits anti-oxidant, anti-tumor, anti-thrombotic, and anti-inflammatory effects [23-26]. Wogonoside not only affects the translation of inducible nitric oxide synthase (iNOS) and cyclooxygenase 2 (COX-2) but also inhibits lipopolysaccharide (LPS)-induced TNF- $\alpha$ and IL-6 expression in RAW264.7 cells [26]. In addition, wogonoside exerts a protective effect in inflammationinduced angiogenesis in endothelial cells [27]. The anti-inflammatory effects of wogonoside in tumors have been associated with inhibition of the PI3K/AKT/ $\mathrm{NF}-\kappa \mathrm{B}$ pathway [25]. After NF- $\kappa \mathrm{B}$ activating, the transcriptional level of HIF-2 $\alpha$ is up-regulated, which is involved in the hypertrophic shift and VEGF generation in OA chondrocytes [18]. We investigated, therefore, the potential of wogonoside as a protective agent for OA treatment by inhibiting inflammation, ECM degradation, hypertrophy, and angiogenesis in chondrocytes via the cross-talk between the PI3K/AKT/NF- $\mathrm{kB}$ and HIF-2 $\alpha$ pathways and by delaying the development of $\mathrm{OA}$ in a rodent model of destabilization of the medial meniscus (DMM).

\section{RESULTS}

\section{Phenotypic determination of primary chondrocytes}

The morphology of primary chondrocytes (passage 2 ) is shown in Figure 1A. The phenotype was determined by Alcian blue staining and immunofluorescence of type II collagen staining, as shown in Figure 1B and 1C.

\section{Effects of wogonoside on chondrocyte viability}

The cytotoxic effects of wogonoside on chondrocytes was determined at various concentrations $(12.5,25,50,100$, and $200 \mu \mathrm{M})$ for 24 and $48 \mathrm{~h}$ using the Cell Counting Kit-8 (CCK8) assay. As shown in Figure $2 \mathrm{~B}$, treatment with $200 \mu \mathrm{M}$ or $100 \mu \mathrm{M}$ wogonoside significantly reduced cell viability at $24 \mathrm{~h}(* * \mathrm{P}<0.01$ vs. untreated cells) and $48 \mathrm{~h}\left({ }^{*} \mathrm{P}<0.05\right.$ vs. untreated cells $)$, respectively, indicating that cell viability is not affected by wogonoside at concentrations up to $50 \mu \mathrm{M}$ before $48 \mathrm{~h}$.Therefore, concentrations of $12.5,25$ and $50 \mu \mathrm{M}$ wogonoside were used for subsequent experiments. 
Effects of wogonoside on the expression of iNOS, COX-2, PGE 2 , NO, TNF- $\alpha$, and IL-6 in IL-1 $\beta-$ induced mouse chondrocytes

We next determined whether wogonoside inhibits iNOS and COX-2 production at the transcriptional and/ or translational level using real-time polymerase chain reaction (RT-PCR) and Western blot analysis. As shown in Figure $3 \mathrm{~A}, 3 \mathrm{C}$ and $3 \mathrm{D}$, wogonoside significantly inhibited the up-regulation of IL-1 $\beta(10 \mathrm{ng} / \mathrm{ml})$-induced mRNA and protein expression of iNOS and COX-2 in a dosedependent manner $(12.5,25$ and $50 \mu \mathrm{M})$. Moreover, the production of endogenous $\mathrm{NO}$ and $\mathrm{PGE}_{2}$ was significantly up-regulated by IL-1 $\beta$ stimulation. However, treatment with wogonoside resulted in decreased NO generation and $\mathrm{PGE}_{2}$ expression in a dose-dependent manner. In addition, a concentration-dependent inhibition of TNF- $\alpha$ and IL-6 production was observed by RT-PCR and enzyme-linked immunosorbent assay (ELISA) (Figure $3 \mathrm{~B}$ and $3 \mathrm{~F}$ ). At the concentration of $12.5 \mu \mathrm{M}$, wogonoside inhibited the mRNA expressions of IL- 6 and TNF- $\alpha$ but have no inhibitory effect on protein expressions. At the concentrations of 25 and $50 \mu \mathrm{M}$, wogonoside significantly inhibited TNF- $\alpha$ and IL- 6 generation at both protein and mRNA levels. It suggests that wogonoside inhibits the production of these inflammatory cytokines at both gene and protein levels in a dose-dependent manner.

\section{Wogonoside protects against IL-1 $\beta$-induced hypertrophic conversion and VEGF generation in mouse chondrocytes}

The expression of collagen X and Runx-2, which are considered markers of chondrocyte hypertrophy, was examined by Western blotting, Both collagen X and Runx-2 were up-regulated in the presence of IL-1 $\beta$, and wogonoside protected chondrocytes against hypertrophic conversion at concentrations of $25 \mu \mathrm{M}\left({ }^{*} \mathrm{P}<0.05\right)$ and $50 \mu \mathrm{M}$ (Figure $4 \mathrm{~A}$ and $4 \mathrm{~B}, * * \mathrm{P}<0.01$ ). Alkaline phosphatase (ALP) activity is another indicator of hypertrophy and mineralization in vitro. Treatment with wogonoside resulted in an inhibition of ALP activity in a dose-dependent manner and reached a statistically significant difference at a concentration of 50 $\mu \mathrm{M}$ compared to other concentrations (Figure 4C and 4D,
A

\section{Primary chondrocyte(P2)}

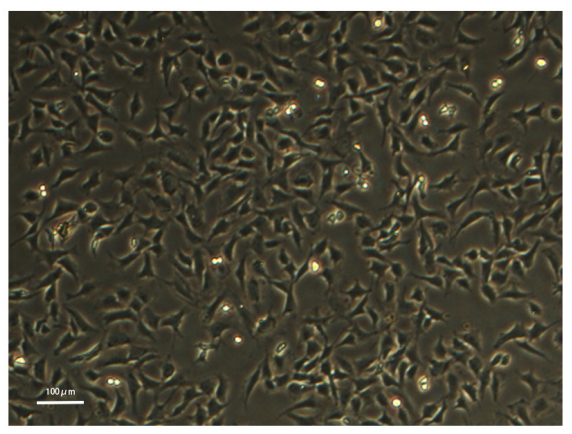

B

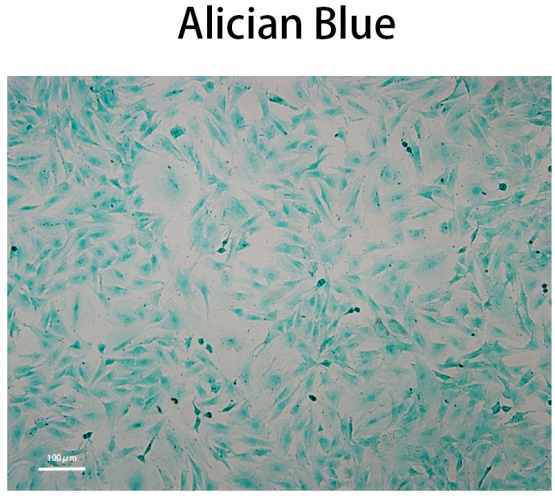

C
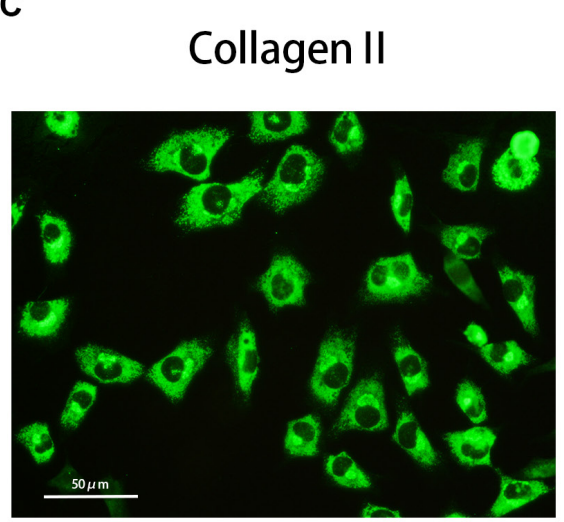

Figure 1: Phenotype determination of mice primary chondrocyte. (A) The morphology of normal passage two primary chondrocytes. (B) Alcian blue stain was performed to stain the proteoglycan in chondrocytes. (C) The representative type two collagen was detected by immunofluorescence.

A

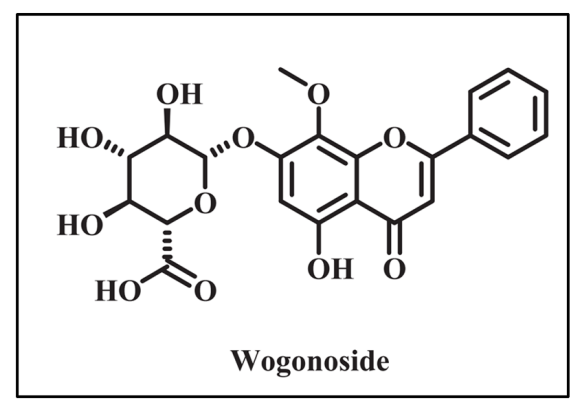

B

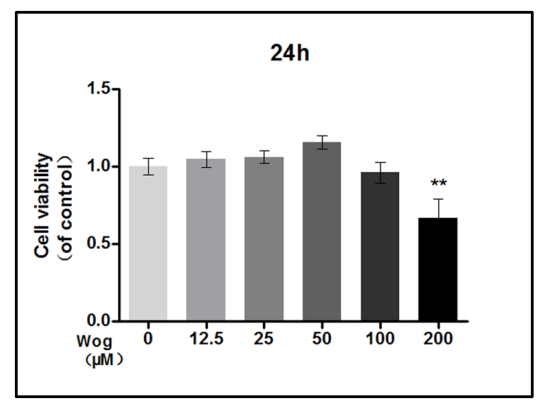

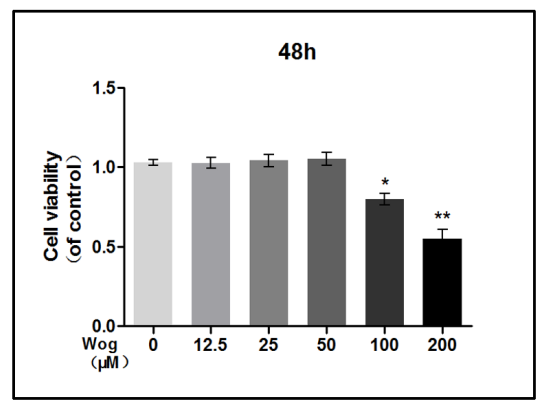

Figure 2: Effects of wogonoside on the cell viability of chondrocytes. (A) Chemical structure of wogonoside. (B) The cytotoxic effect of wogonoside on chondrocytes was determined at various concentrations for 24 and 48 hours using a CCK8 assay. The values presented are the means \pm S.D. of three independent experiments. $* \mathrm{P}<0.05, * * \mathrm{P}<0.01$ vs. control group. 
A

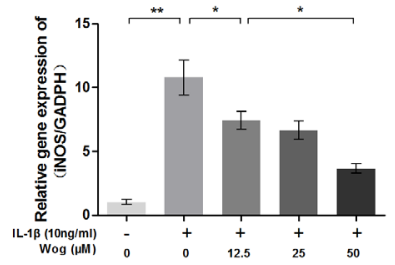

C

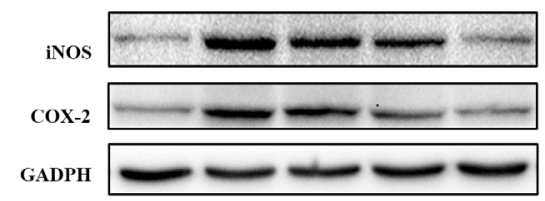

IL-1ß (10ng/ml)

$\begin{array}{llllll}\text { Wog (uM) } & 0 & 0 & 12.5 & 25 & 50\end{array}$

E

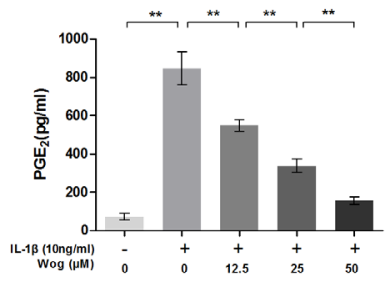

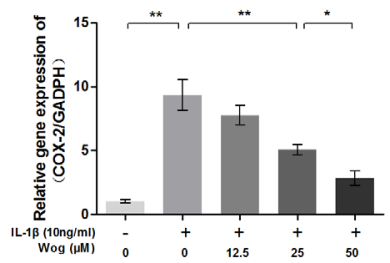

B
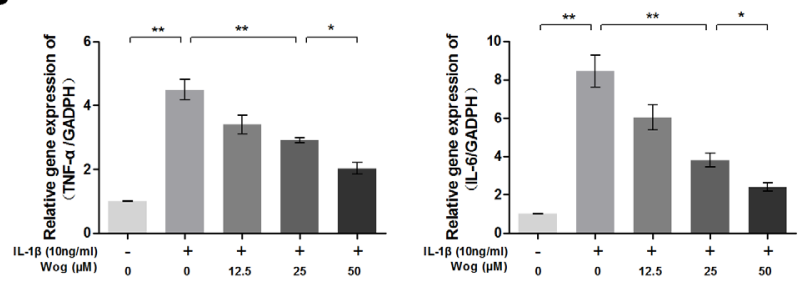

D
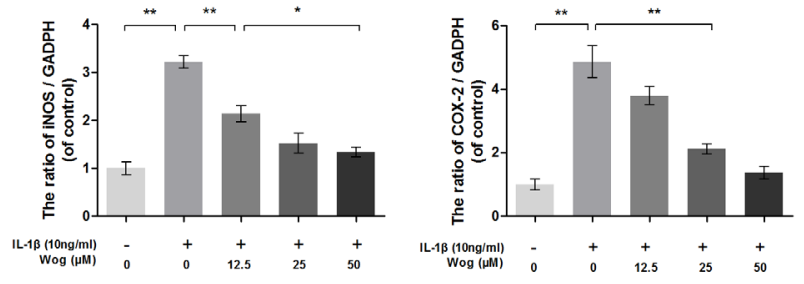

$\mathbf{F}$

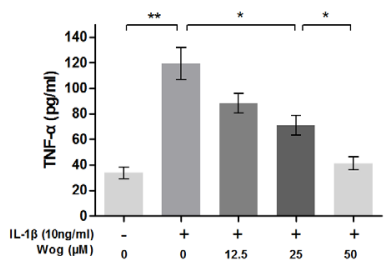

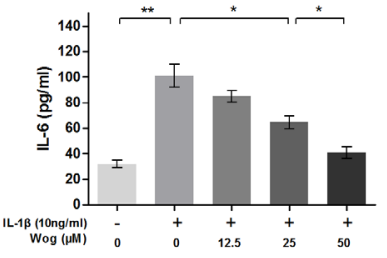

Figure 3: Wogonoside inhibit inflammatory effect in mice chondrocyte. (A-B) The mRNA expression of iNOS, COX-2, TNF- $\alpha$ and IL-6 were measured by real-time PCR. (C-D) The protein expression of iNOS and COX-2 in chondrocytes treated as above. (E-F) Effect of wogonoside on IL-1 $\beta$-induced PGE 2 , NO, TNF- $\alpha$ and IL-6 production in mice chondrocytes. The data in the figures represent the averages \pm S.D. Significant differences between the treatment and control groups are indicated as $* * P<0.01,{ }^{*} \mathrm{P}<0.05, \mathrm{n}=3$.

A

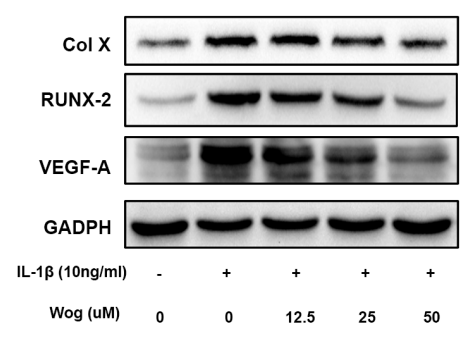

C

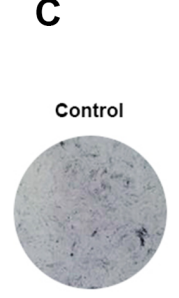

B
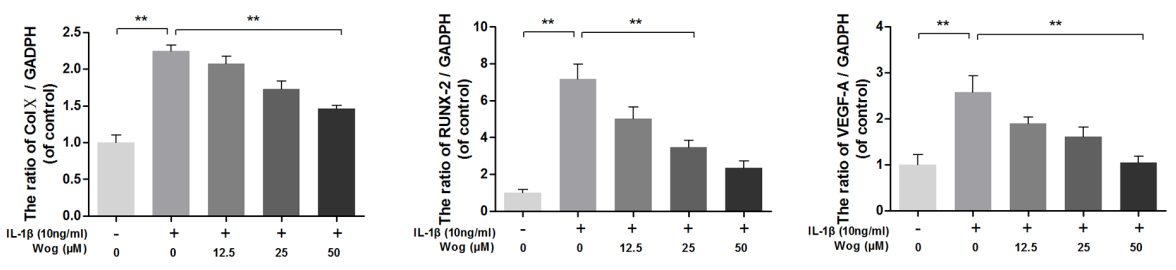

D

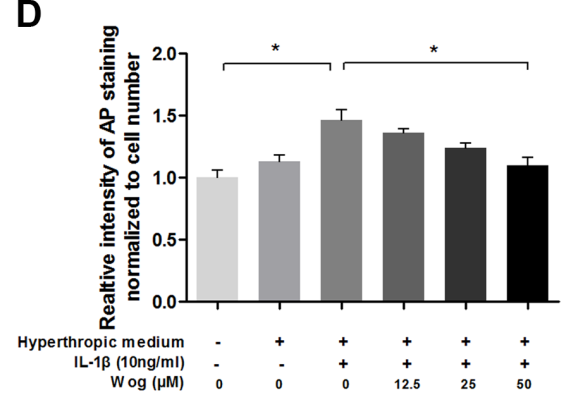

Figure 4: Wogonoside inhibit hypertrophic conversion and VEGF generation in mice chondrocyte. (A-B) The protein expression of Col X, RUNX-2, and VEGF-A in chondrocytes treated as above. (C-D) wogonoside ameliorate IL-1 $\beta$-induced chondrocyte hypertrophy and mineralization (as assessed by AP staining). The data in the figures represent the averages \pm S.D. Significant differences between the treatment and control groups are indicated as $* * \mathrm{P}<0.01,{ }^{*} \mathrm{P}<0.05, \mathrm{n}=3$. 
$* \mathrm{P}<0.05)$. Conversely, IL-1 $\beta$ led to the generation of VEGF, which is associated with the OA process. Pretreatment with wogonoside markedly attenuated the increase in VEGF compared to treatment with IL-1 $\beta$ alone at concentrations of $25 \mu \mathrm{M}(* \mathrm{P}<0.05)$ and $50 \mu \mathrm{M}(* * \mathrm{P}<0.01)$.

\section{Effects of wogonoside on ECM synthesis in IL- $1 \beta$-induced mouse chondrocytes}

To evaluate chondrocyte degeneration, we investigated the function of ECM replacement of chondrocytes under IL-1 $\beta$ stimulation with or without wogonoside pretreatment by Western blot analysis. As shown in Figure $5 \mathrm{~A}$ and $5 \mathrm{~B}$, IL- $1 \beta$ significantly inhibited Sox-9 transcription and decreased type II collagen and aggrecan synthesis (all $* * \mathrm{P}<0.01)$. All alterations in IL-1 $\beta$ expression were reversed by pretreatment with wogonoside, especially at a concentration of $50 \mu \mathrm{M}$ $(* * \mathrm{P}<0.01)$. In addition, immunofluorescence showed that type II collagen-positive proteins mainly localized in the cytoplasm, consistent with the Western blot analysis (Figure 5C and 5D).

\section{Effects of wogonoside on ECM degradation in

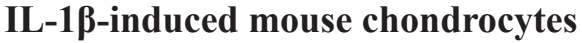

MMPs and ADAMTS are regarded as major factors of ECM degradation. Western blot analysis showed that IL-1 $\beta$ significantly up-regulated the expression of MMPs such as MMP-3, MMP-9 and especially MMP-13 (Figure $6 \mathrm{~A}$ and $6 \mathrm{~B}$, all $* * \mathrm{P}<0.01)$. However, wogonoside reversed this destructive effect in a dose-dependent manner. Moreover, immunofluorescence staining of MMP-13 was consistent with the Western blot analysis. Similar results were obtained for ADAMTS-5 (Figure 6C and 6D).

\section{Time-dependent effects of IL-1 $\beta$ on the phosphorylation of IKK/IKB $\alpha /$ p65 and HIF-2 $\alpha$ expression}

To determine the time at which NF- $\kappa \mathrm{B}$ is phosphorylated, the phosphorylation levels of $\mathrm{p} 65, \mathrm{I} \kappa \mathrm{B} \alpha$ and IKK $\alpha / \beta$ were assessed in IL- $1 \beta$-stimulated chondrocytes by Western blot at the indicated time points. Western blot analysis at four time points revealed that IL- $1 \beta$ markedly induced the phosphorylation of IKK $\alpha / \beta, \mathrm{I} \kappa \mathrm{B} \alpha$ and NF- $\kappa \mathrm{B}$ p65 in a time-dependent manner, with the phosphorylation response reaching a peak at approximately $2 \mathrm{~h}$ and decreasing rapidly at $4 \mathrm{~h}$. Moreover, the expression of HIF$2 \alpha$ after IL- $1 \beta$ stimulation was consistent with the changes in the NF- $\kappa$ B pathway (Figure 7).

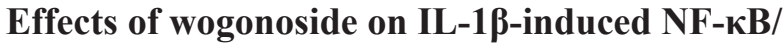 HIF-2 $\alpha$ activation}

To examine the effects of wogonoside on NF$\kappa \mathrm{B}$ pathway activation, the phosphorylation levels of $\mathrm{p} 65, \mathrm{I} \kappa \mathrm{B} \alpha$ and $\mathrm{IKK} \alpha / \beta$ and the expression of HIF-2 $\alpha$

C

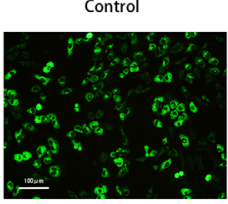

IL-1 $\beta$
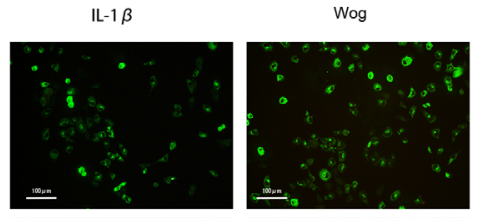

DAPI
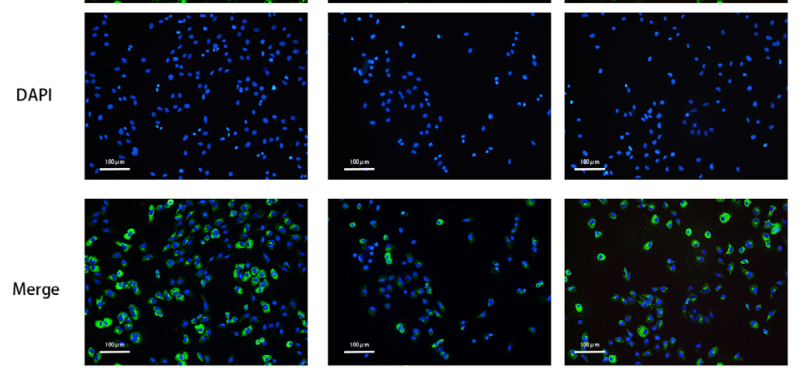

D
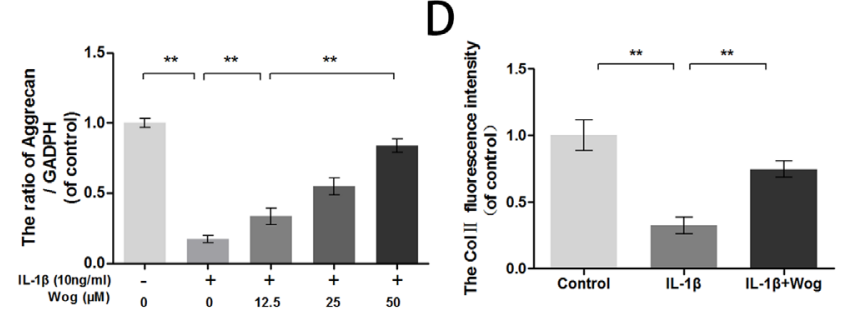

Figure 5: Wogonoside promote extracellular matrix synthesis from IL-1ß induced mice chondrocyte. (A-B) The protein expression of Col II, Sox-9, and aggrecan in chondrocytes treated as above. (C-D) The representative collagen II was detected by the immunofluorescence combined with DAPI staining for nuclei (original magnification $\times 100$, scale bar: $100 \mu \mathrm{m}$ ). The data in the figures represent the averages \pm S.D. Significant differences between the treatment and control groups are indicated as $* * \mathrm{P}<0.01, * \mathrm{P}<0.05, \mathrm{n}=3$. 


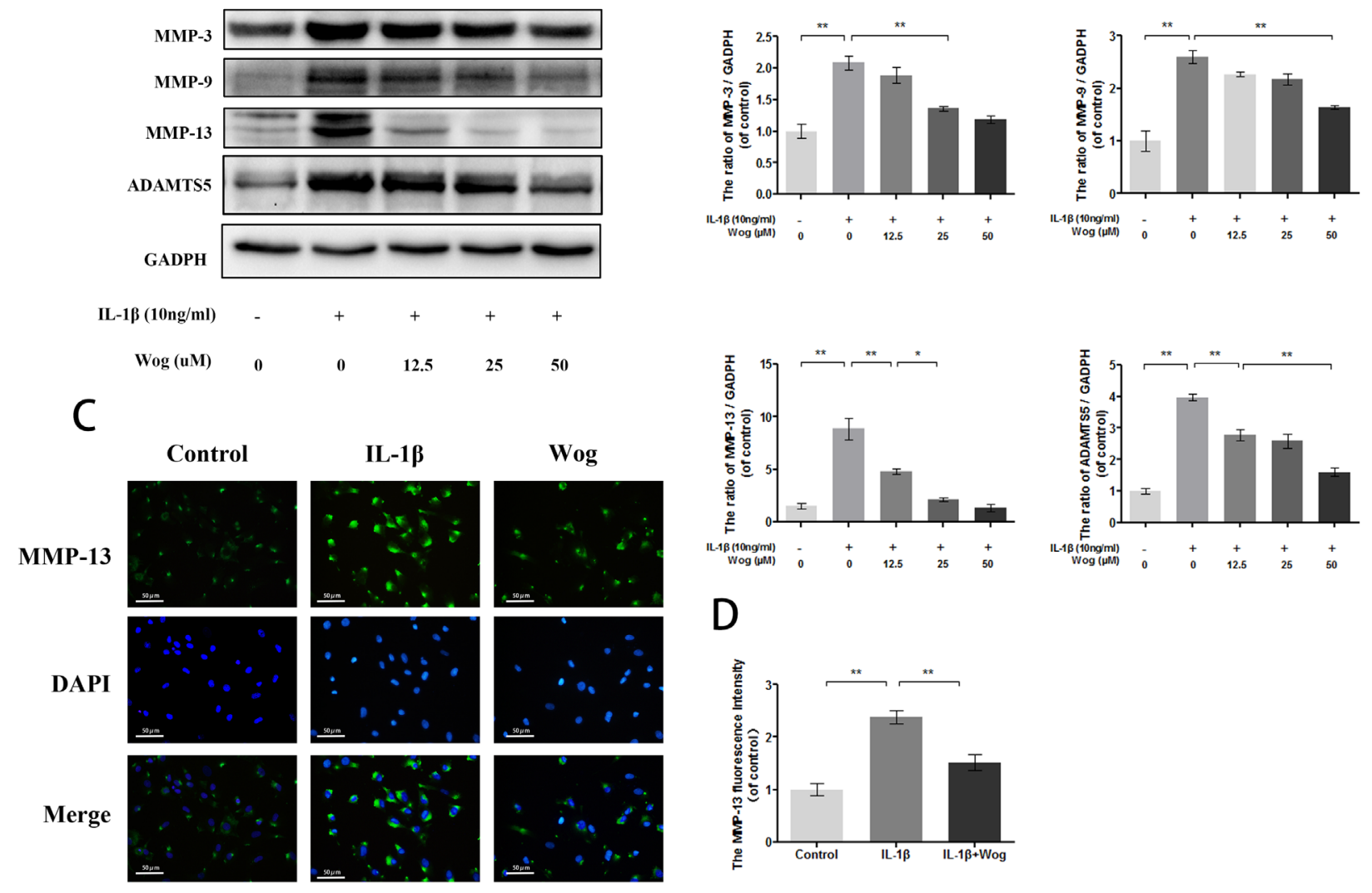

Figure 6: Wogonoside inhibit extracellular matrix degradation from IL-1ß induced mice chondrocyte. (A-B) The protein expression of MMP-3, MMP-9, MMP-13 and ADAMTS-5 in chondrocytes treated as above. (C-D) The representative MMP-13 was detected by the immunofluorescence combined with DAPI staining for nuclei (original magnification $\times 200$, scale bar: $50 \mu \mathrm{m}$ ). The data in the figures represent the averages \pm S.D. Significant differences between the treatment and control groups are indicated as $* * \mathrm{P}<0.01$, $* \mathrm{P}<0.05, \mathrm{n}=3$.

A

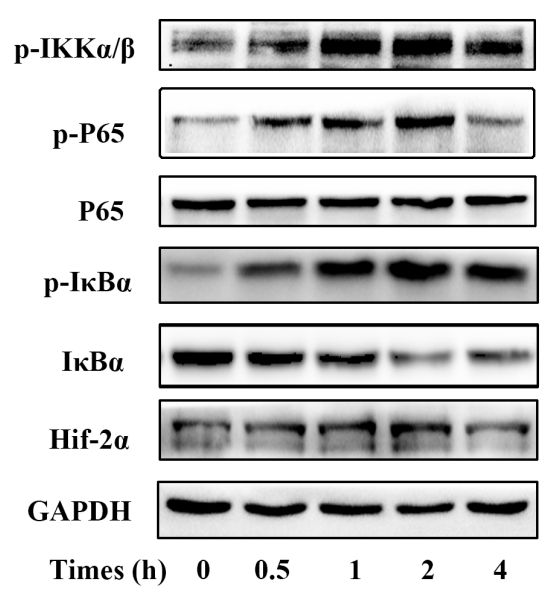

B
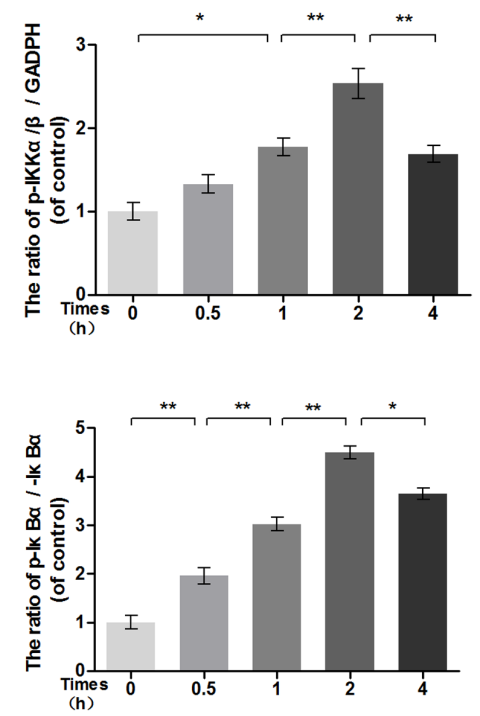
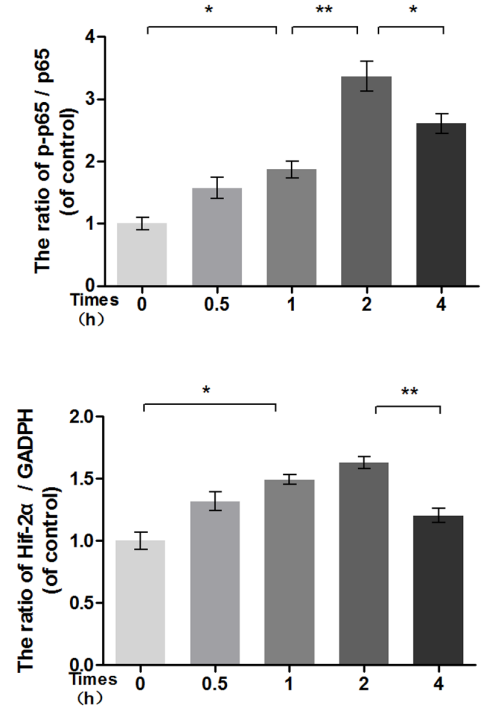

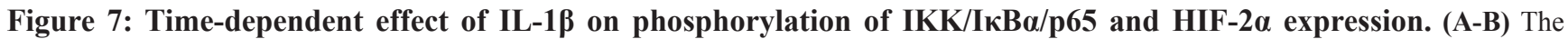
protein expression of $\mathrm{p}-\mathrm{IKK} \alpha / \beta, \mathrm{p}-\mathrm{I} \kappa \mathrm{B} \alpha, \mathrm{I} \kappa \mathrm{B} \alpha, \mathrm{p}-\mathrm{p} 65, \mathrm{p} 65$ and HIF-2 $\alpha$ in chondrocytes treated as above. The data in the figures represent the averages \pm S.D. Significant differences between the treatment and control groups are indicated as $* * P<0.01,{ }^{*} P<0.05, n=3$. 
were assessed in IL-1 $\beta$-stimulated chondrocytes by Western blot analysis at $2 \mathrm{~h}$. IL- $1 \beta$ markedly induced the phosphorylation of IKK $\alpha / \beta, \mathrm{I} \kappa \mathrm{B} \alpha$ and p65 and upregulated HIF-2 $\alpha$ expression (Figure $8 \mathrm{~A}$ and $8 \mathrm{~B}$, all $* * \mathrm{P}<0.01)$. However, this response was significantly decreased by wogonoside pretreatment at a concentration of $50 \mu \mathrm{M}$ (Figure $8 \mathrm{~A}$ and $8 \mathrm{~B}$, all $* \mathrm{P}<0.01$ ).

Indirect immunofluorescence staining of p65 was performed to reveal the translocation of p65 from the cytoplasm to the nucleus in chondrocytes in response to NF$\kappa \mathrm{B}$ activation by IL-1 $\beta$. The administration of chondrocytes were divided into three groups: (1) control group; (2) IL$1 \beta$ stimulated group; (3) IL-1 $\beta$ plus wogonoside treatment group. In the control group, the majority of $\mathrm{p} 65$ protein was located in the cytoplasm. Upon IL-1 $\beta$ stimulation, p65-positive proteins stained intensively in the nucleus of chondrocytes, leaving the cytoplasm unstained, indicating the nuclear translocation of the NF- $\kappa$ B subunit. However, pretreatment with wogonoside inhibited the translocation of p65 subunits into the nucleus (Figure 8C). These immunomorphological findings suggest an inhibitory effect of wogonoside on the IL-1 $\beta$-induced p65 nuclear dislocation in chondrocytes and are consistent with the inhibition of the NF- $\mathrm{BB}$ pathway observed by Western blot.

HIF-2 $\alpha$ expression was also detected by indirect immunofluorescence staining (Figure $8 \mathrm{D}$ and $8 \mathrm{E}$ ). The results indicated that a considerable amount of HIF-2 $\alpha$ is localized to the nucleus upon IL-1 $\beta$ stimulation for $2 \mathrm{~h}$ compared to control chondrocytes. Fluorescence intensity was inhibited by wogonoside pretreatment for $24 \mathrm{~h}$, indicating that the protective effects of wogonoside are associated with HIF-2 $\alpha$ inhibition.

\section{Effects of wogonoside on IL-1 $\beta$-induced activation of Stat3, ERK1/2, TRAF6, IRAK1 and PI3K/AKT}

To clarify further the anti-inflammatory mechanism of wogonoside, several upstream signaling molecules associated with IL-1 $\beta$ induced inflammation in chondrocytes were be examined, such as Signal Transducer and Activator of Transcription (Stat3), Extracellular signal-regulated kinase 1/2 (ERK1/2), TNF Receptor Associated Factor (TRAF6), Interleukin-1 Receptor Associated Kinase (IRAK1) and PI3K/AKT. As shown in Figure 9, all of these signaling molecules were activated with IL- $1 \beta$ treatment. Although pretreated with wogonoside did not decrease the protein expressions of stat3, ERK1/2, TRAF6 and IRAK1, the catalytic subunit (PI3K-p110) and the regulatory subunit of PI3K (PI3K-p85) were significantly down-regulated by wogonoside in IL-1 $\beta$-stimulated chondrocytes according to results of western blot analysis. IL-1 $\beta$-induced AKT phosphorylation was also inhibited by wogonoside.
$\mathbf{A}$

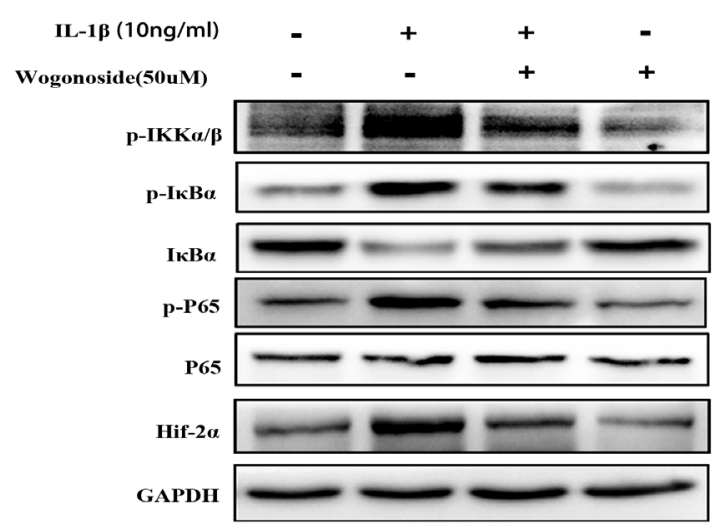

B
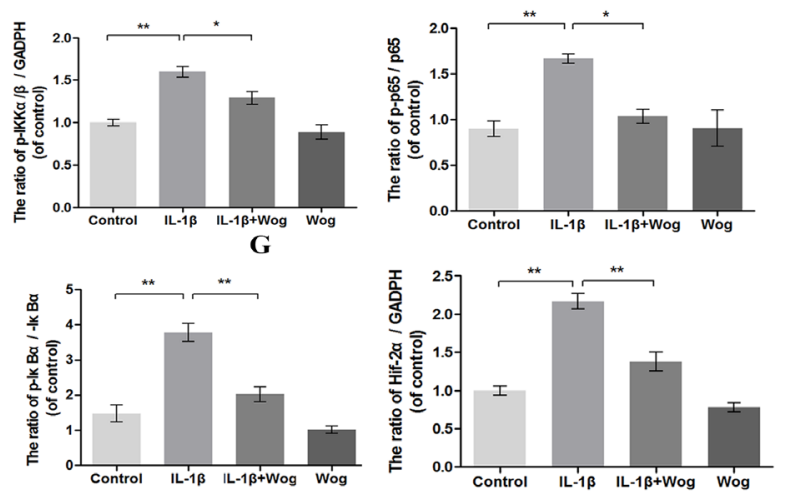

C
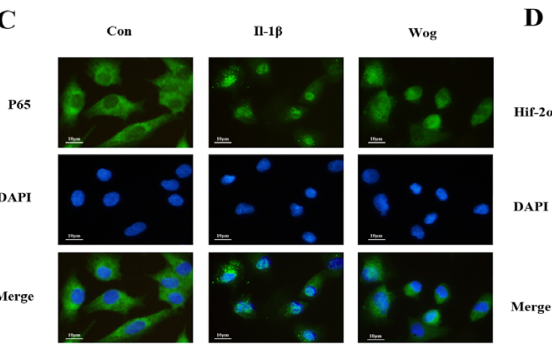

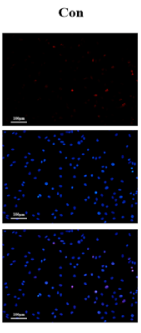

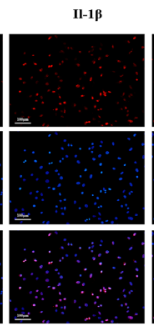
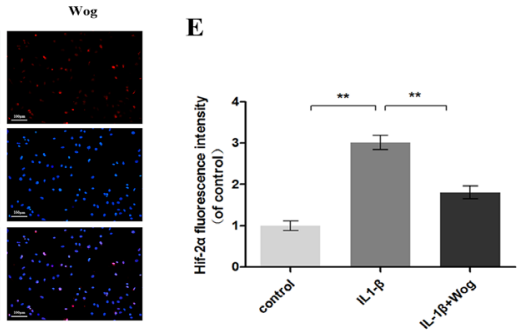

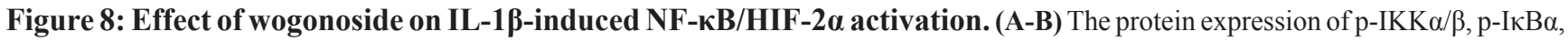
$\mathrm{I} \kappa \mathrm{B} \alpha, \mathrm{p}-\mathrm{p} 65$, p65 and HIF-2 $\alpha$ in chondrocytes treated as above. (C) The nuclei translocation of p65 was etected by the immunofluorescence combined with DAPI staining for nuclei (original magnification $\times 400$, scale bar: $10 \mu \mathrm{m}$ ). (D-E) The representative HIF-2 $\alpha$ was detected by the immunofluorescence combined with DAPI staining for nuclei (original magnification $\times 100$, scale bar: $100 \mu \mathrm{m}$ ). The data in the figures represent the averages \pm S.D. Significant differences between the treatment and control groups are indicated as $* * \mathrm{P}<0.01, * \mathrm{P}<0.05, \mathrm{n}=3$. 


\section{Pharmacokinetic profle of wogonoside}

The pharmacokinetic profle of wogonoside at doses of $20 \mathrm{mg} / \mathrm{kg}$ in rats (equal $40 \mathrm{mg} / \mathrm{kg}$ in mice) are presented in (Figure 10A). Each point represents a mean value of six serum concentrations. After intragastric administration, wogonoside was quickly absorbed into the bloodstream and reached first peak serum concentration $\left(\mathrm{C}_{\max } 1\right)$ of $1378.25 \pm 105.13 \mathrm{ng} / \mathrm{ml}$ at $0.54 \pm 0.25 \mathrm{~h}\left(\mathrm{~T}_{\max } 1\right)$. The second peak was reached at $5.67 \pm 0.82 \mathrm{~h}\left(\mathrm{~T}_{\max } 2\right)$ with the second peak serum concentration $\left(\mathrm{C}_{\max } 2\right)$ of $1131.07 \pm 127.94 \mathrm{ng} / \mathrm{ml}$. Additionally, the area under the serum concentration-time curve $\left(\mathrm{AUC}_{0-24}\right)$ at $24 \mathrm{~h}$ is $10655.58 \pm 693.41 \mathrm{~h} * \mathrm{ng} / \mathrm{ml}$.

\section{Wogonoside ameliorates OA development in the mouse model of DMM}

To investigate the protective effects of wogonoside in OA development in vivo, a surgically induced mouse model of DMM was established, followed by intragastric administration of $40 \mathrm{mg} / \mathrm{kg}$ wogonoside dissolved in $0.5 \%$ Carboxymethylcellulose
(CMC) or vehicle $(0.5 \% \mathrm{CMC}$ alone) once daily for 8 weeks. Histological analysis of OA was evaluated by Safranin $O$ staining for cartilage, and hematoxylin and eosin (H\&E) staining for synovitis. Osteoarthritis Research Society International (OARSI) scores and synovitis scores were used for the quantitative analysis. As shown in the Safranin O staining (Figure 10C), the cartilage surface was smooth and showed positive red staining in the sham control group. The OA group showed cartilage erosion, apparent hypocellularity and massive proteoglycan loss compared to the sham control group. However, the wogonoside group exhibited less proteoglycan loss compared to the OA group. Consistent with the Safranin O staining, the OARSI scores (Figure 10D) of the OA group were markedly higher $(9.13 \pm 1.46)$ than those of the sham control (1.25 $\pm 0.20)$. In contrast, the wogonoside group displayed clearly lower OARSI scores $(5.50 \pm 1.06)$ than the OA group. In addition, the synovial thickening and hypercellularity was presented in OA group, whereas, wogonoside treatment alleviated synovitis compared to the OA group (Figure 10E). What's more, according to the X-ray shown, the OA group showed severe knee varus, aberrant narrowing of joint space and increase of
A

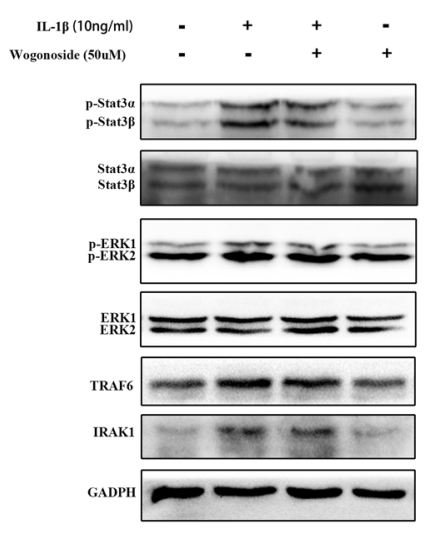

C

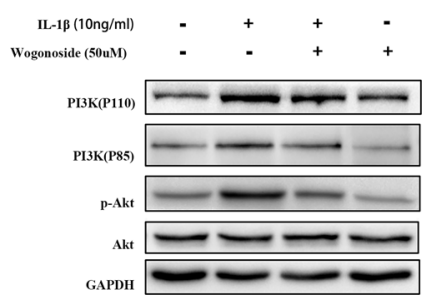

B
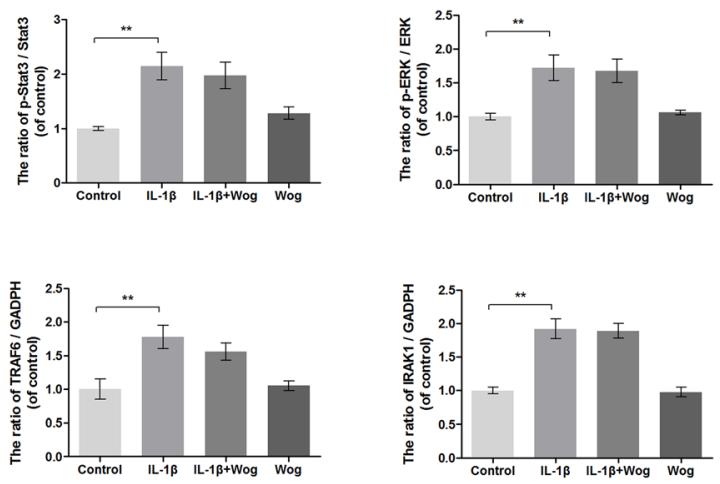

D

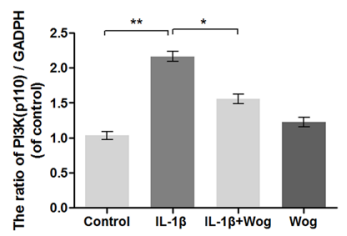

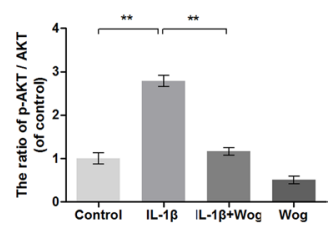

Figure 9: Effect of wogonoside on IL-1及-induced PI3K/AKT activiation. (A-B) The protein expression of p-Stat3, Stat3, p-ERK1/2, ERK1/2, TRAF6 and IRAK1 in chondrocytes treated as above. (C-D) The protein expression of PI3K(p110), PI3K(p85), p-AKT and AKT in chondrocytes treated as above. The data in the figures represent the averages \pm S.D. Significant differences between the treatment and control groups are indicated as $* * \mathrm{P}<0.01, * \mathrm{P}<0.05, \mathrm{n}=3$. 
cartilage surface density compared to the sham group. Nevertheless, although the narrowing of joint space exits, the calcification of cartilage surface was milder in wogonoside treatment group (Figure 10B). Together, these results indicate that wogonoside protects against OA development in vivo via inhibiting the loss of proteoglycan, cartilage calcification and synovitis.

\section{Wogonoside attenuates ECM degradation and hypertrophy of chondrocytes in vivo via HIF-2 $\alpha$ inhibition}

To demonstrate the mechanism of the chondroprotective effects of wogonoside in vivo, immunohistochemical staining of HIF-2 $\alpha$, MMP-13,
A

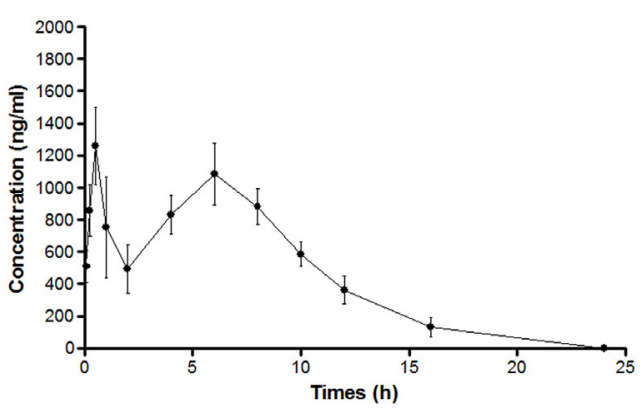

C

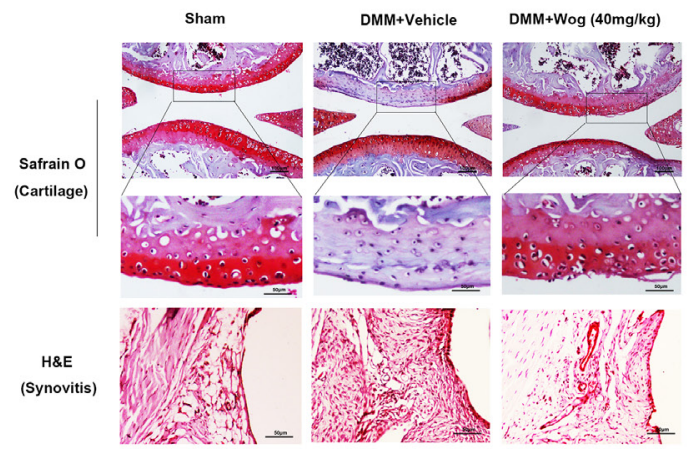

$\mathbf{F}$
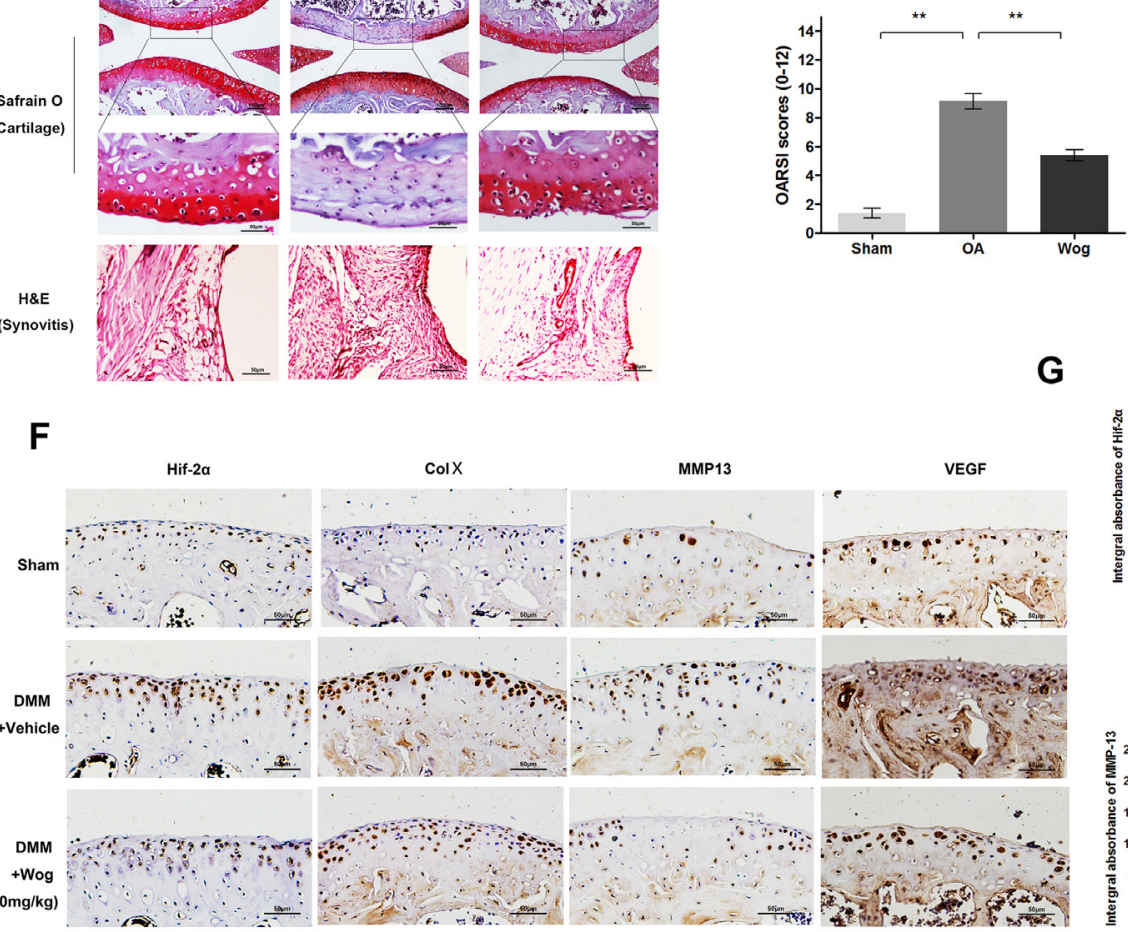

G
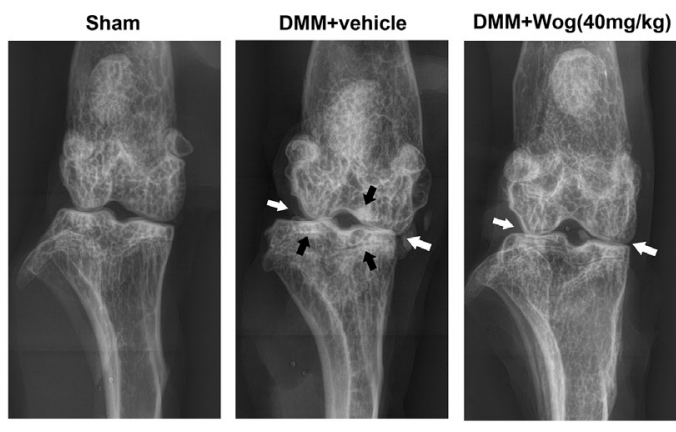

E
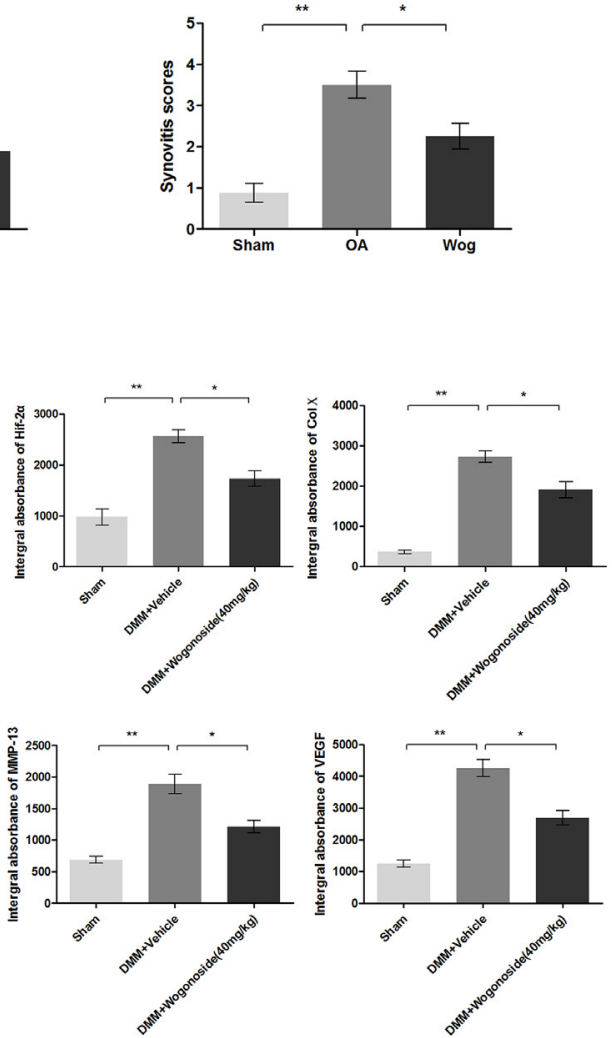

Figure 10: Wogonoside ameliorates OA development in mice DMM model in vivo. (A) Concentration-time curve of wogonoside administration in rats. (B) Digital X-ray image of mouse knee joints from different experimental groups. Narrowing of joint space was found in both OA and treatment group (white arrows), the calcification of cartilage surface was obviously shown in OA group (black arrows). (C) Representative S-O staining of cartilage and H\&E staining of synovitis from different experimental groups at 8 weeks post-surgery (original magnification $\times 100$ or $\times 400$, scale bar: $100 \mu \mathrm{m}$ or $50 \mu \mathrm{m}$ ). (D) Diagrams showed the OARIS socres of cartilage. (E) Diagrams showed the scores of synovitis. (F-G) immunohistochemical staining of HIF-2 $\alpha$, Col X, MMP-13 and VEGF-A expression in the cartilage samples (original magnification $\times 100$, scale bar: $50 \mu \mathrm{m}$ ). The data in the figures represent the averages \pm S.D. Significant differences between the treatment and control groups are indicated as $* * \mathrm{P}<0.01, * \mathrm{P}<0.05, \mathrm{n}=3$. 
collagen $X$, and VEGF was performed. HIF-2 $\alpha-$, MMP13-, collagen X-, and VEGF-positive areas that were elevated in the cartilage of the OA group compared to the sham group were markedly reversed after wogonoside administration (Figure 10F and 10G).

\section{DISCUSSION}

The main finding of this study is that wogonoside can reverse IL-1 $\beta$-induced $\mathrm{PI} 3 \mathrm{~K} / \mathrm{AKT}$ activation and nuclear dislocation of NF- $\kappa \mathrm{B}$ in mouse chondrocytes, which subsequently protect against ECM degradation and hypertrophic conversion in the presence of IL-1 $\beta$. In addition, the in vivo results suggest that wogonoside may play a protective role in OA via HIF- $2 \alpha$ inhibition.

With the rapid aging of the population, the incidence rates of OA have been continuously increasing in recent years [28]. However, the pathogenesis of OA development is not clear and no effective intervention exists to prevent the progression of OA unless total knee arthroplasty is performed at the end stage of OA $[29,30]$. Although nonsteroidal anti-inflammatory drugs (NSAIDs) have been widely used for OA treatment in clinical practice during the last few years, these agents only relieve the clinical symptoms temporarily and fail to prevent the progression of OA; they also have many side effects [22]. Therefore, it is necessary to identify novel chemopreventive agents that can reverse cartilage destruction during the progression of OA with minimal or no side effects or toxicity.

Wogonoside, a glucuronide metabolite of the bioactive flavonoid wogonin, exhibits anti-inflammatory, anti-viral, anti-oxidant, and anti-cancer properties [31]. Previous studies have reported the anti-inflammatory effects of wogonoside in several diseases [25-27]. For the first time, we investigated its anti-inflammatory effects in chondrocytes. Furthermore, several in vitro and in vivo studies have confirmed that the inflammatory environment plays a negative role in the stability of chondrocyte phenotype and hemostasis of the ECM, which aggravates cartilage destruction and promotes $\mathrm{OA}$ progression [8-10]. Therefore, we further investigated whether the administration of wogonoside can reverse these conditions caused by inflammation and explored the potential molecular mechanisms involved.

One of the most apparent phenomena in the inflammatory environment in chondrocytes is the increase in NO, a reactive molecule originating from the guanidine nitrogen of L-arginine, which is catalyzed by

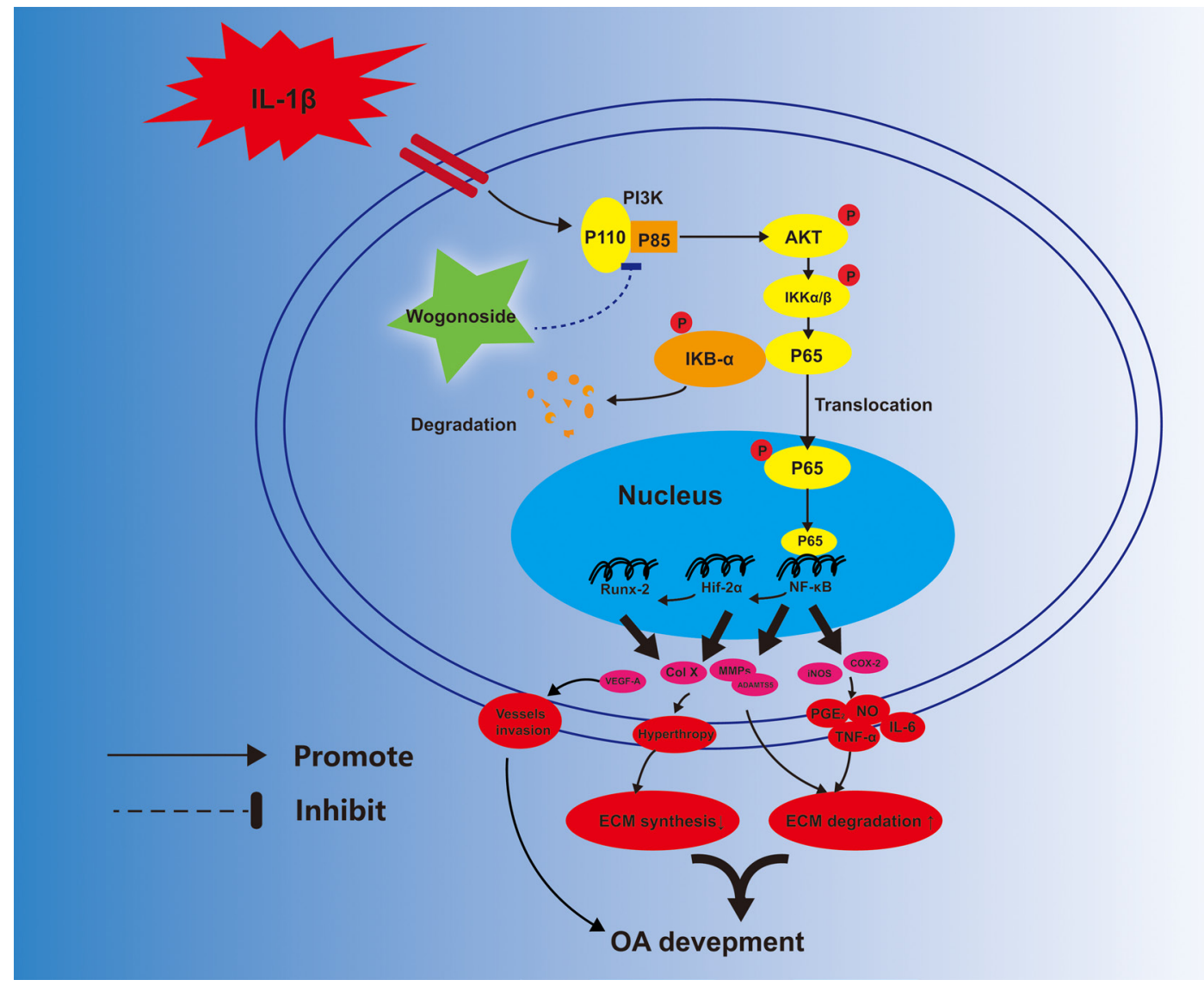

Figure 11: Potential molecular mechanism involved in wogonoside treatment in chondrocytes. Wogonoside attenuated IL-1 $\beta$ induced ECM degradation and hypertrophy in mice chondrocyte via suppressing NF-Kb/ HIF-2 $\alpha$ activation by PI3K/Akt pathway. 
iNOS [32]. NO suppresses collagen II and proteoglycan synthesis and stimulates the activation of MMPs to cause ECM degradation [33]. Conversely, $\mathrm{PGE}_{2}$ is a principal mediator of inflammation that is converted from IL-1 $\beta$-induced endogenous arachidonic acid via the COX-2 catalytic reactions and is associated with cartilage destruction due to its powerful activation on MMPs and other inflammatory mediators [34, 35]. All of these factors, as well as TNF- $\alpha$ and IL-6, are important inflammatory cytokines in OA development [36]. In this study, we found that the over-production of $\mathrm{PGE}_{2}$ and $\mathrm{NO}$, as well as the up-regulation of COX-2 and iNOS, at both the gene and protein levels are inhibited by wogonoside following IL-1 $\beta$ stimulation. Similar results were also found for TNF- $\alpha$ and IL-6. These results are consistent with those from Yang et al., whose research revealed that wogonoside inhibits LPS-induced inflammatory activation in RAW264.7 macrophages [26]. Therefore, we surmised that the anti-inflammatory effects of wogonoside may be associated with the inhibition of TNF- $\alpha$ and IL-6 expression, as well as the decreased production of NO and $\mathrm{PGE}_{2}$ via targeting iNOS and COX-2.

A stable phenotype is essential for ECM replacement in normal hyaline cartilage in chondrocytes. However, chronic stimulation of inflammatory cytokines can lead to an unrestricted hypertrophic shift. This aberrant terminal differentiation results in excessive calcification of chondrocytes in OA development [8]. Type $\mathrm{X}$ collagen, MMP-13 and RUNX-2 are major markers of hypertrophic chondrocytes, which are markedly elevated following IL- $1 \beta$ stimulation, as shown in our study, and are reduced by wogonoside pretreatment. Similar changes were observed regarding VEGF, which is also related to chondrocyte hypertrophy. However, the main function of VEGF is associated with angiogenesis, which is crucial for OA progression according to recent research [37]. Moreover, the up-regulation of ALP activity, a marker of the calcification of chondrocytes, represents the terminal change of hypertrophic chondrocytes. Our study revealed that AP staining was consistent with the Western blot analysis of hypertrophy-related proteins, indicating that wogonoside attenuates the increase in ALP activity from IL- $\beta$-induced chondrocytes.

The ECM secreted by chondrocytes mediates the principle function of cartilage. Sox-9 is the core gene for type II collagen synthesis [7]. In contrast, MMPs and ADAMTS contribute to ECM catabolism [11-13]. Protecting ECM hemostasis is the pivotal and ultimate goal for most interventions in OA treatment [6]. According to our research, in the presence of IL- $\beta$, wogonoside not only enhanced Sox-9 transcription and promoted synthesis of the most prominent components of the ECM, including type II collagen and aggrecan, but also inhibited the catabolism of ECM components by down-regulating MMPs and ADAMTS-5, which helped maintain ECM homeostasis.
To elucidate the mechanism by which wogonoside unites anti-inflammation, anti-hypertrophy and anticatabolism of the ECM in chondrocytes, we further explored the cross-talk between the PI3K/AKT, NF$\kappa \mathrm{B}$ and HIF- $2 \alpha$ signaling pathways. NF- $\mathrm{KB}$ plays a key regulatory role in inflammatory mediators involved in the pathogenesis of OA [38]. According to previous studies, IL-1 $\beta$ stimulation triggers the phosphorylation of the catalytic subunits of IKK (IKK $\alpha$ and IKK $\beta$ ), as well as the binding protein of p65 (IKB $\alpha$ ), which consequently frees p65 and translocates it from the cytosol to the nucleus and leads to the production of catabolic enzymes, cytokines and inflammatory mediators [16]. Furthermore, several studies have demonstrated that NF- $\mathrm{kB}$ activation is associated with downstream regulators of terminal chondrocyte differentiation, including HIF- $2 \alpha$ and Runx2. Additionally, as shown in our study, the up-regulation of HIF- $2 \alpha$ expression was followed by NF-kB activation, both of which were affected in a time-dependent manner. It was consistent with the studies of Chun et al [19] and Kawaguchi et al [20], indicating that HIF-2 $\alpha$ is located downstream of the NF-kB pathway, which relates inflammation with the phenotypic and functional changes in IL-1 $\beta$-induced chondrocytes. For the first time, our data reveal that wogonoside inhibits IL-1 $\beta$-induced inflammation, ECM degradation and hypertrophy by suppressing NF- $\mathrm{kB} / \mathrm{HIF}-$ $2 \alpha$ signaling in chondrocytes. Additionally, wogonoside has been reported to inhibit the inflammatory effects in macrophages and tumor cells via NF- $\mathrm{kB}$ inhibition [25, $39]$. Thus, the results from previous studies along with ours indicate that the anti-inflammatory effects of wogonoside may be closely related to the inhibition of NF- $\mathrm{KB}$ activation. The benefits of phenotypic and functional alterations may also be attributed to the vertical inhibition of HIF- $2 \alpha$.

Several upstream signaling molecules, such as Stat3, ERK1/2, TRAF6, IRAK1 and PI3K/AKT were reported to be involved in IL-1 $\beta$ induced inflammation in chondrocytes. In our studies, all of these protein expressions were examined. The protein expression of Stat3, ERK1/2, TRAF6 and IRAK1 were not altered after wogonoside administration with or without IL-1 $\beta$ stimulation. However the activation of PI3K/AKT after IL-1 $\beta$ stimulation was inhibit by wogonoside (Figure 9). $\mathrm{PI} 3 \mathrm{~K} / \mathrm{AKT}$ is one of the most well-studied upstream signaling pathways of intracellular message trafficking. It regulates a cascade of changes through its broad target proteins such as mechanistic target of rapamycin (mTOR), $\mathrm{NF}-\kappa \mathrm{B}$, glycogen synthase kinase 3 beta (GSK-3 $\beta$ ), and $\mathrm{p} 53$, all of which are involved in the OA process [17]. Therefore, we further investigated the correlation between $\mathrm{NF}-\mathrm{\kappa B}$ and PI3K/AKT signaling during wogonoside treatment with respect to OA. The PI3K family consists of three classes, Class I, Class II and Class III, among which the Class I PI3Ks are responsible for the production of PIP3, which binds to the pleckstrin homology domain of AKT and phosphoinoside-dependent protein kinase 1 
(PDK1), resulting in the phosphorylation of AKT [4042]. In the current study, IL-1 $\beta$ stimulation markedly up-regulated the protein levels of the catalytic subunit (PI3K-p110) and the regulatory subunit (PI3K-p85) of PI3K, which catalyzes the production of PIP3 and leads to the phosphorylation of AKT followed by activation of

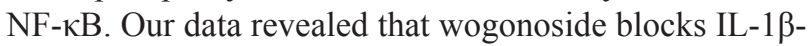
induced AKT activation via inhibition of PI3K-p110 and PI3K-p85, which further targets the downstream NF- $\mathrm{kB} /$ HIF- $2 \alpha$ molecules.

In order to examine the effects of wogonoside in vivo, a pharmacokinetic study of wogonoside was conducted. Due to the limited blood volume in mice, the rats were used into our studies through intragastric administration. The dosage to rats was converted by using body surface area normalized methods [48] The results of time-concentration curve showed a double peaks phenomena after administration. The peak serum concentration (Cmax) of 1825.4 and $6635.7 \mathrm{nM}$ at 0.5 $\mathrm{h}$ and $8 \mathrm{~h}$ respectively post-dose for dose $20 \mathrm{mg} / \mathrm{kg}$. This could be due to enterohepatic circulation, which might prolong the effective duration of agents. The area under the curve $\left(\mathrm{AUC}_{0-24}\right)$ at $24 \mathrm{~h}$ is $10655.58 \pm 693.41 \mathrm{~h} * \mathrm{ng} / \mathrm{ml}$. All of these data indicated that the oral administration of wogonoside at $20 \mathrm{mg} / \mathrm{kg}$ once a day in rat (equally $40 \mathrm{mg} / \mathrm{kg}$ in mice) showed a sufficient systemic exposure and good dose proportionality for pharmacodynamics evaluation. And it is an important property for wogonoside in its translational development from animal to human subjects.

The loss of proteoglycans in the cartilage surface, hypertrophic changes, degradation of the ECM, angiogenesis, and synovitis are involved in OA progression [8]. Among them, the decrease in proteoglycans is the main characteristic of cartilage degeneration. Hypertrophic changes and degradation of the ECM also play key roles in OA development. Angiogenesis causes vessels to invade the hyaline cartilage and results in the calcification of cartilage, which is believed to contribute to the pathogenesis of OA [37]. Moreover, synovitis is closely related to clinical symptoms such as joint dysfunction and may aggravate cartilage degeneration [43]. DMM was demonstrated to be a reliable and effective method to establish an animal OA model for in vivo analysis [44]. Thus, in the present study, mouse OA models induced by DMM were used to examine the chondroprotective effects of wogonoside in vivo. Treatment with wogonoside dramatically reduced the OARSI scores as well as the scores of severity of synovitis in mouse OA models. Conversely, wogonoside inhibited MMP-13, type X collagen and VEGF generation by surgical intervention via HIF- $2 \alpha$ inhibition, indicating that HIF- $2 \alpha$ is a potential target of wogonoside that could be used for OA treatment.

In conclusion, the current study demonstrates that wogonoside prevents IL-1 $\beta$-associated ECM degradation and hypertrophic conversion in mouse chondrocytes. The potential mechanism involved in its protective effects is the reversal of inflammation-related destruction via inhibiting NF- $\mathrm{KB} / \mathrm{HIF}-2 \alpha$ activation through the PI3K/ AKT pathway (Figure 11). Moreover, oral administration of wogonoside not only reduced cartilage degradation, hypertrophic conversion and angiogenesis but also relieved synovitis in mouse OA models via HIF- $2 \alpha$ inhibition. Therefore, wogonoside may serve as a promising effective chemotherapeutic agent for the treatment of $\mathrm{OA}$ in the future.

\section{MATERIALS AND METHODS}

\section{Ethics statement}

All surgical interventions, treatments and postoperative animal care procedures were performed in strict accordance with the Animal Care and Use Committee of Wenzhou Medical University (wydw20140129).

\section{Reagents and antibodies}

Wogonoside (purity $>98 \%$ ), was purchase from Nantong Feiyu Biological Technology Co, ltd (Nantong, China). Carboxymethylcellulose (CMC) and type II collagenases were purchased from Sigma-Aldrich (St Louis, MO, USA). Recombinant human IL-1 $\beta$ was purchased from PeproTech (NJ, USA). The primary antibody against collagen II, aggrecan, MMP-9, MMP13, ADAMTS5, collagen X, HIF-2 $\alpha$, TRAF6, p-ERK1/2, ERK1/2, p-Stat3, Stat3 and GADPH were acquired from Abcam (Cambridge, UK), MMP-3 and iNOS antibodies were obtained from Sigma-Aldrich (St Louis, MO, USA). Sox-9 antibody was obtained from Santa Cruz Biotechnology (Santa Cruz, CA, USA); Anti-VEGF-A, Anti-Runx-2, Anti-IRAK1, goat anti-rabbit, and antimouse IgG-HRP was from Bioworld (OH, USA) and antibodies against COX-2, PI3K(p110), PI3K(p85), AKT, p-AKT, p-IKK $\alpha / \beta$, IкB $\alpha, p-I \kappa B \alpha, p 65$, and p-p65 were purchased from Cell Signaling Technology (Danvers, MA, USA); Alexa Fluor ${ }^{\circledR} 488$ labeled and Alexa Fluor ${ }^{\circledR 594}$ labeled Goat Anti-Rabbit IgG $(\mathrm{H}+\mathrm{L})$ second antibody was purchased from Jackson ImmunoResearch (West Grove, PA, USA). The 4', 6-diamidino-2-phenylindole (DAPI) was obtained from Beyotime (Shanghai, China). The cell culture reagents were purchased from Gibco (Grand Island, NY, USA).

\section{Primary mice chondrocytes culture}

Ten immature C57BL/6 mice (5 males and 5 females, 10 days) were euthanized with an overdose of sodium pentobarbital. The knee cartilages of mice were collected carefully under aseptic conditions by a 
dissecting microscope, and the tissues were treated with $2 \mathrm{mg} / \mathrm{ml}(0.1 \%)$ collagenase II for $4 \mathrm{~h}$ at $37^{\circ} \mathrm{C}$. Next, the digested cartilage tissues were suspended and seeded into tissue culture flasks. The chondrocytes grow in DMEM/ F12 (Gibco, Invitrogen, Grand Island, NY) with 10\% fetal bovine serum (FBS; Hyclone, Thermo Scientific, Logan, UT, USA) and $1 \%$ penicillin/streptomycin antibiotics (Gibco, Invitrogen, Grand Island, NY) in the incubator maintained at $5 \% \mathrm{CO}_{2}$ at $37^{\circ} \mathrm{C}$. The medium was changed firstly after $24 \mathrm{~h}$ incubation. When up to $80 \%$ to $90 \%$ confluency, the cells were harvested by using $0.25 \%$ Trypsin-EDTA (Gibco, Invitrogen). Then, cells were replanted into $10 \mathrm{~cm}$ culture plates at the appropriate density. The second-passage chondrocytes were used for all of our experiment due to no significant changes was noticed during cells passaging from passage 0 to passage 2. The chondrocytes were cultured in the incubator maintained at $5 \% \mathrm{CO}_{2}$ at $37^{\circ} \mathrm{C}$ and the complete medium was changed every other day.

\section{Alcian blue staining}

The phenotype of chondrocytes identified by staining for sulfate proteoglycan with Alcian blue as previously described [45]. The passage two chondrocytes were washed twice with cold PBS and fixed with $4 \%$ paraformaldehyde at room temperature for $15 \mathrm{~min}$. After washed twice by PBS again, the chondrocyte will be pretreated with $0.1 \mathrm{M} \mathrm{HCl}$ for $3 \mathrm{~min}$, Next, the cells were stained 30min with 0.1\% Alcian Blue 8GX (SigmaAldrich, St Louis, MO, USA). After washing 3 times with distilled water, the stained cells were observed and captured observed with invert microscope (Leica).

\section{Cell viability assay}

The cytotoxicity of wogonoside on chondrocytes were detected with the cell counting kit-8 (CCK8; Dojindo Co, Kumamoto, Japan) according to the manufacturer's protocol. Firsrly, the second-passage chondrocytes were transferred to 96 -well plates $(50000$ cell $/ \mathrm{cm}^{2}$ ) and incubated in different concentration of wogonoside $(12.5,25,50,100,200 \mu \mathrm{M})$ for $24 \mathrm{~h}$. At the indicated time, the cells were washed with phosphatebuffered saline (PBS), and then $100 \mu \mathrm{l}$ of DMEM/F12 containing $10 \mu \mathrm{l}$ of CCK-8 solution was added to each well of the plate and incubated for another $2 \mathrm{~h}$ at $37^{\circ} \mathrm{C}$. The absorbance of the wells was then measured at 450 $\mathrm{nm}$ using a micro-plate reader. All experiments were performed triplicately.

\section{NO, PGE 2 , TNF- $\alpha$, IL-6 measurement}

The interaction of $\mathrm{NO}$ in culture medium was measured by Griess reagent as previously described [46]. The concentreation of $\mathrm{PGE}_{2}, \mathrm{TNF}-\alpha$ and IL-6 in cell culture supernatants was detected by using commercial
ELISA kits (R\&D Systems, Minneapoils, MN) according to the manufacturer's instructions. All assays were performed in triplicate.

\section{Real-time PCR}

The total RNA of chondrocytes stimulated with IL$1 \beta(10 \mathrm{ng} / \mathrm{ml})$ and wogonoside at various concentrations were extracted from the cells in $6-\mathrm{cm}$ culture plates using TRIzol reagent (Invitrogen). 1000ng of total RNA was reverse transcribed to synthesize cDNA (MBI Fermantas, Germany). For the quantitative realtime PCR (qPCR), a total $10 \mu \mathrm{l}$ of reaction volume was used, including $5 \mu \mathrm{l}$ of $2 \times \mathrm{SYBR}$ Master Mix, $0.25 \mu \mathrm{l}$ of each primer and $4.5 \mu$ l of diluted cDNA. Parameters of RT-PCR were: $10 \mathrm{~min} 95^{\circ} \mathrm{C}$, followed by 40 cycles of $15 \mathrm{~s} 95{ }^{\circ} \mathrm{C}$ and $1 \mathrm{~min} 60{ }^{\circ} \mathrm{C}$. The reaction was performed using CFX96Real-Time PCR System (BioRad Laboratories, California, USA). The cycle threshold $(\mathrm{Ct})$ values were collected and normalized to the level of GAPDH. The level of relative mRNA of each target gene was calculated by using the $2^{-\Delta \Delta \mathrm{Ct}}$ method. The primers of COX-2, iNOS, IL-6, TNF- $\alpha$ were designed with the aid of NCBI Primer-Blast Tool. (https://www.ncbi.nlm.nih. gov/tools/primer-blast/), which were listed as follows: COX-2 (F) 5'- TCCTCACATCCCTGAGAACC-3', (R) 5'- GTCGCACACTCTGTTGTGCT-3'; iNOS (F) 5'- GACGAGACGGATAGGCAGAG-3', (R) 5'- CACATGCAAGGAAGGGAACT-3'; IL-6, (F) 5'-CCGGAGAGGAGACTTCACAG-3', (R) 5'- TCCACGATTTCCCAGAGAAC-3'; TNF- $\alpha$ (F) 5'-ACGGCATGGATCTCAAAGAC-3', (R) 5'GTGGGTGAGGAGCACGTAGT- 3'.

\section{Western blotting}

The total protein extracted from chondrocytes was isolated using RIPA lysis buffer with $1 \mathrm{mM}$ PMSF (Phenylmethanesulfonyl fluoride) and on the ice for 10 min followed by 15 min centrifugation at $12000 \mathrm{rpm}$ and $4^{\circ} \mathrm{C}$, and then protein concentration was measured using the BCA protein assay kit (Beyotime). $40 \mathrm{ng}$ of protein was separated by sodium dodecylsulfate-polyacrylamide gel electrophoresis (SDS PAGE) and transferred to a polyvinylidene difluoride membrane (Bio-Rad, USA). After blocking with 5\% nonfat milk for $2 \mathrm{~h}$, the membranes were incubated with the primary antibody against collagen II (1:1000), Aggrecan (1:1000), Sox9 (1:250), Col X(1:500), Runx-2(1:500), VEGF-A (1:500), GADPH (1:5000), iNOS (1:1000), COX-2 (1:1000), MMP-3 (1:1000), MMP-9 (1:1000), ADAMTS-5 (1:1000), p-IKK $\alpha / \beta$ (1:500), p-p65 (1:1000), p65 (1:1000), p-IкB $\alpha$

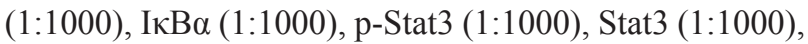
p-ERK1/2 (1:1000), ERK1/2 (1:1000), TRAF6 (1:1000), IRAK1 (1:1000), PI3K(p110) (1:1000), PI3K(p85) (1:1000), p-AKT (1:1000), AKT (1:1000) and HIF-2 $\alpha$ 
(1:1000) overnight at $4{ }^{\circ} \mathrm{C}$, and followed by subsequently incubation with respective secondary antibodies for $2 \mathrm{~h}$ at room temperature. After 3 times washing with TBST, the blots were visualized by electrochemiluminescence plus reagent (Invitrogen). Finally, the intensity of these blots were quantified with Image Lab 3.0 software (Bio-Rad).

\section{Immunofluorescence}

For collagen II and MMP-13 staining, the chondrocytes were planted in glass plates in a six-well plate and then the cells were treated with $10 \mathrm{ng} / \mathrm{ml} \mathrm{IL-}$ $1 \beta$ or being co-treated with $10 \mathrm{ng} / \mathrm{ml} \mathrm{IL-1 \beta}$ and $50 \mu \mathrm{M}$ wogonoside for $24 \mathrm{~h}$ in medium after incubated with serum-starved medium overnights. For p65 and HIF$2 \alpha$ staining, the duration of IL- $1 \beta$ and wogonoside treatment was down to $2 \mathrm{~h}$. After treatments. The samples were rinsed three-times in PBS before fixation using 4\% paraformaldehyde and followed by permeation using the $0.1 \%$ Triton X-100 diluted in PBS for $15 \mathrm{~min}$. Then the cells were blocked with $5 \%$ bovine serum albumin for 1 $\mathrm{h}$ at $37^{\circ} \mathrm{C}$, rinsed with $\mathrm{PBS}$ and incubated with primary antibodies which diluted in PBS: collagen II (1:200), MMP-13 (1:200), p65 (1:200) and HIF-2 $\alpha$ (1:400) in a humid chamber overnight at $4{ }^{\circ} \mathrm{C}$. On the next day, the glass plates were washed and incubated with Alexa Fluor ${ }^{\circledR} 488$ labeled or Alexa Fluor ${ }^{\circledR} 594$ conjugated second antibodies $(1: 400)$ for $1 \mathrm{~h}$ at room temperature and labeled with DAPI for $5 \mathrm{~min}$. Finally, three fields of each slides were chosen randomly for microscopic observation with a fluorescence microscope (Olympus Inc., Tokyo, Japan), and the fluorescence intensity was measured using Image $\mathrm{J}$ software 2.1 (Bethesda, MDUSA) by observers who were blinded to the experimental groups.

\section{In vitro chondrocyte hypertrophy and mineralization assay}

The hypertrophy and mineralization of chondrocyte was determined by AP staining as previous described [47]. Cells were seeded into 24-well plates and incubated with differentiation medium for 14 days, which composed of DMEM/F12 supplemented with $1 \%(\mathrm{v} / \mathrm{v})$ insulintransferrin-selenium (BD Biosciences), and 1\% (v/v) antibiotic/antimycotic solution, $50 \mathrm{mg} / \mathrm{ml}$ ascorbate-2phosphate, $40 \mathrm{mg} / \mathrm{ml}$ L-proline, $100 \mathrm{nM}$ dexamethasone, and $1 \mathrm{nM}$ triiodothyronine (all from Sigma). After that, the activity of alkaline phosphatase (AP), a marker of chondrocyte hypertrophy, was assayed using a BCIP/ NBT AP color development kit (Beyotime Institute of Biotechnology). DAPI was used to stain nuclei. The APpositive area and intensity in 5 randomly selected fields viewed under an invert microscope (Leica) were measured using Image Pro Plus 6.0 (Media Cybernetics, Rockville, MD, USA). Relative intensity of AP staining was normalized to cell number.

\section{Pharmacokinetics study of wogonoside in rat}

Pharmacokinetics of wogonoside was conducted in SD rats (200-250g) by intragastric administration at dose of $20 \mathrm{mg} / \mathrm{kg}$. This concentration was equal to the dosage of $40 \mathrm{mg} / \mathrm{kg}$ in mice in our study according to a body surface area normalized methods [48]. The rats were allowed food and water ad libitum before pharmacokinetics experiment. About $200 \mu \mathrm{L}$ of blood was taken from tail vein of rats at $5 \mathrm{~min}, 15 \mathrm{~min}, 30 \mathrm{~min}$, $1,2,4,6,8 \mathrm{~h}, 10 \mathrm{~h}, 12 \mathrm{~h}, 16 \mathrm{~h}$ and $24 \mathrm{~h}$ post-dose. After centrifugation of blood samples at $13,000 \mathrm{rpm}$ at $4^{\circ} \mathrm{C}$ for $5 \mathrm{~min}$, plasm samples were transferred into Eppendorf tube. $100 \mu \mathrm{L}$ of each serum was processed by adding 3 -folds excess of methanol containing $10 \mathrm{ul}$ internal standard (IS) solution followed by vortexing for $1 \mathrm{~min}$. The tube was then centrifuged at 13,000 $\mathrm{rpm}$ at $4^{\circ} \mathrm{C}$ for $10 \mathrm{~min}$. Then the supernatant was filtrated through $0.22 \mathrm{~m}$ membrane and an aliquot were injected into UPLC-MS/MS for analysis. Quantification was performed in MRM mode of the transitions $\mathrm{m} / \mathrm{z}$ $461.2 \rightarrow 285.2$ for wogonoside, $m / z \quad 461.2 \rightarrow 285.2$ for IS solution respectively. SCIEX Analyst software (version 1.4.2) was used for data acquisition and analysis. The pharmacokinetic parameters were calculated by the noncompartmental analysis of plasma concentration versus time data using the DAS 3.0 software (Mathematical Pharmacology Professional Committee of China, Shanghai, China).

\section{Animal model}

Sixty Ten-week-old C57BL/6 male wild-type (WT) mice were purchased from Animal Center of Chinese Academy of Sciences Shanghai, China. The protocol for animal care and use conformed to the Guide for the Care and Use of Laboratory Animals of the National Institutes of Health and was approved by the Animal Care and Use Committee of WenzhouMedical University. The osteoarthritis was induced by surgical destabilization of the medial meniscus (DMM) as previously described [44]. In brief, after anaesthesia with intraperitoneally injection of $2 \%(\mathrm{w} / \mathrm{v})$ pentobarbital (40 mg/kg,) the joint capsule of right knee was opened with an incision just medial to the patellar tendon and the medial meniscotibial ligament was transected with microsurgical scissors. As a control, surgery consisting of an arthrotomy without the transaction of medial meniscotibial ligament, was also performed in the left knee joint of mice and the joint was used as sham group. After surgery, the mice were randomly divided into three groups: sham group, vehicle group and wogonoside treatment group. In the wogonoside treatment group, the mice were given wogonoside $40 \mathrm{mg} / \mathrm{kg}$ every day via gastric intubation until sacrificed. 


\section{Histopathologic analysis}

The mice were sacrificed by an intraperitoneal overdosage injection of $10 \%$ chloral hydrate and the knee joint were harvested on 8 weeks after surgery. The specimens were fixed in $\mathrm{n} 4 \%(\mathrm{v} / \mathrm{v})$ neutral paraformaldehyde for $24 \mathrm{~h}$ and decalcified in neutral $10 \%(\mathrm{v} / \mathrm{v})$ EDTA solution for 1 month. Following dehydrated and embedded in paraffin, the tissues were cut into 5- $\mu \mathrm{m}$ sagittal sections. Slides of each joint were stained with safranin O-fast green(S-O) and H\&E. The cellularity and morphology of cartilage and subchondral bone were examined by another group of experienced histology researchers in a blinded manner using a microscope, and evaluated by using a Osteoarthritis Research Society International (OARSI) scoring system for medial femoral condyle and medial tibial plateau as described previously [49]. The severity of synovitis was graded using a scoring system which was previously described [50]: Enlargement of the synovial lining cell layer on a scale of $0-3(0=1-2$ cells, $1=2-4$ cells, $2=4-9$ cells and $3=10$ or more cells) and density of cells in the synovial stroma on a scale of $0-3(0=$ normal cellularity, $1=$ slightly increased cellularity, $2=$ moderately increased cellularity and $3=$ greatly increased cellularity).

\section{X-ray imaging method}

After 8 weeks of surgery within or not treatment, the animals were given the X-ray examination. X-ray imaging was performed on all mice to evaluate the joint space and calcification changes of cartilage surface using a digital X-ray machine (Kubtec Model XPERT.8; KUB Technologies Inc.). Proper images were obtained in the following settings: $50 \mathrm{Kv}$ and $160 \mu \mathrm{A}$.

\section{Immunohistochemical examination}

The sections embedded in paraffin were deparaffinized and rehydrated and then the endogenous peroxidase activity was need to be blocked by $3 \%$ hydrogen peroxide. After that, the sections were incubated with $0.4 \%$ pepsin (Sangon Biotech, Shanghai, P.R. China) in $5 \mathrm{~m} \mathrm{M} \mathrm{HCl}$ at $37^{\circ} \mathrm{C}$ for $20 \mathrm{~min}$ for antigen retrieval. and nonspecific binding sites was blocked by $5 \%$ bovine serum albumin for $30 \mathrm{~min}$ at room temperature. The sections were then incubated with the primary antibody (anti-HIF$2 \alpha, 1: 100$; anti-Col X, 1:200, anti-MMP-13, 1:200; antiVEGF-A, 1:100) overnight at $4{ }^{\circ} \mathrm{C}$. Finally, the sections were incubated with an appropriate HRP-conjugated secondary antibody (Santa Cruz Biotechnology, Dallas, TX, USA) and counterstained with hematoxylin. Images were saved using Image-Pro Plus software, version 6.0 (Media Cybernetics, Rockville, MD, USA), and the integral absorbance values were used as indicators of HIF$2 \alpha$, Col10A1, MMP-13 and VEGF-A expression levels.
At least three sections from each specimen were used to analyze the expression of these proteins.

\section{Statistical analysis}

The experiments were at least performed triplicately. The results were presented as mean \pm S.D. Statistical analyses were performed using SPSS statistical software program 20.0. Data were analyzed by one-way analysis of variance (ANOVA) followed by the Tukey's test for comparison between control and treatment groups. Nonparametric data (Pfirrmann grading) were analyzed by the Kruskal-Wallis $\mathrm{H}$ test. P values less than 0.05 were considered significant.

\section{Abbreviations}

OA, osteoarthritis; ECM, extracellular matrix; $\mathrm{PGE}_{2}$, prostaglandin $\mathrm{E} 2 ; \mathrm{NO}$, nitric oxide; COX2 , cyclooxygenase- 2 ; iNOS, inducible nitric oxide synthase; ADAMTS, thrombospondin motifs; MMPs, metalloproteases; NF-кB, nuclear factor kappa B; IKK, I-кB kinase; PI3K, phosphatidylinositol-3-kinase; HIF$2 \alpha$, hypoxia-inducible factors two alpha; VEGF, vascular endothelial growth factor; NSAIDs, non-steroidal antiinflammatory drugs; BSA, bovine serum albumin; DAPI, diamidinophenyl-indole; CMC, carboxymethylcellulose; IL-1 $\beta$, interleukin-1 beta; TNF- $\alpha$, tumor necrosis factor alpha; IL-6, interleukin-6; PBS, phosphate-buffered saline; DMM, destabilization of the medial meniscus.

\section{Author contributions}

Conceived and designed the experiments: QT HXL XLZ. Performed the experiments: QT GZ ZHF YC CGW YTL. Analyzed the data: QT JXX MJT. Contributed reagents/materials/analysis tools: DHC DZ. Wrote the paper: QT HXL. Pharmacokinetic analysis ZYH. English checking: MN.

\section{ACKNOWLEDGMENTS}

This study was supported by National Natural Science Foundation of China (NO.81501869).

\section{CONFLICTS OF INTEREST}

The authors declare no conflicts of interest.

\section{REFERENCES}

1. Lane NE, Shidara K, Wise BL. Osteoarthritis year in review 2016: clinical. Osteoarthritis Cartilage. 2017; 25: 209-215.

2. Glyn-Jones S, Palmer AJ, Agricola R, Price AJ, Vincent TL, Weinans H, Carr AJ. Osteoarthritis. Lancet. 2015; 386: 376-387. 
3. Varady NH, Grodzinsky AJ. Osteoarthritis year in review 2015: mechanics. Osteoarthritis Cartilage. 2016; 24: 27-35.

4. Li YS, Xiao WF, Luo W. Cellular aging towards osteoarthritis. Mech Ageing Dev. 2017; 162: 80-84.

5. Scanzello CR. Chemokines and inflammation in osteoarthritis: insights from patients and animal models. J Orthop Res. 2017; 35: 735-739.

6. Olivotto E, Otero M, Marcu KB, Goldring MB. Pathophysiology of osteoarthritis: canonical NF- $\kappa \mathrm{B} / \mathrm{IKK} \beta$ dependent and kinase-independent effects of IKK $\alpha$ in cartilage degradation and chondrocyte differentiation. RMD Open. 2015; 1: e000061.

7. DeLise AM, Fischer L, Tuan RS. Cellular interactions and signaling in cartilage development. Osteoarthritis Cartilage. 2000; 8: 309-334.

8. van der Kraan PM, van den Berg WB. Chondrocyte hypertrophy and osteoarthritis: role in initiation and progression of cartilage degeneration? Osteoarthritis Cartilage. 2012; 20: 223-232.

9. Dreier R. Hypertrophic differentiation of chondrocytes in osteoarthritis: the developmental aspect of degenerative joint disorders. Arthritis Res Ther. 2010; 12: 216.

10. Goldring SR, Goldring MB. The role of cytokines in cartilage matrix degeneration in osteoarthritis. Clin Orthop Relat Res. 2004; 427: S27-36.

11. Abramson SB, Attur M, Amin AR, Clancy R. Nitric oxide and inflammatory mediators in the perpetuation of osteoarthritis. Curr Rheumatol Rep. 2001; 3: 535-541.

12. Kelwick R, Desanlis I, Wheeler GN, Edwards DR. The ADAMTS (A disintegrin and metalloproteinase with thrombospondin motifs) family. Genome Biol. 2015; 16: 113.

13. Goldring MB, Otero M. Inflammation in osteoarthritis. Curr Opin Rheumatol. 2011; 23: 471-478.

14. Santangelo KS, Nuovo GJ, Bertone AL. In vivo reduction or blockade of interleukin-1beta in primary osteoarthritis influences expression of mediators implicated in pathogenesis. Osteoarthritis Cartilage. 2012; 20: 1610-1618.

15. Kumar A, Takada Y, Boriek AM, Aggarwal BB. Nuclear factor-kappaB: its role in health and disease. J Mol Med (Berl). 2004; 82: 434-448.

16. Csaki C, Mobasheri A, Shakibaei M. Synergistic chondroprotective effects of curcumin and resveratrol in human articular chondrocytes: inhibition of IL-1betainduced NF-kappaB-mediated inflammation and apoptosis. Arthritis Res Ther. 2009; 11: R165.

17. Chen J, Crawford R, Xiao Y. Vertical inhibition of the PI3K/ Akt/mTOR pathway for the treatment of osteoarthritis. J Cell Biochem. 2013; 114: 245-249.

18. Zhang FJ, Luo W, Lei GH. Role of HIF-1alpha and HIF2alpha in osteoarthritis. Joint Bone Spine. 2015; 82: 144-147.
19. Yang S, Kim J, Ryu JH, Oh H, Chun CH, Kim BJ, Min BH, Chun JS. Hypoxia-inducible factor-2alpha is a catabolic regulator of osteoarthritic cartilage destruction. Nat Med. 2010; 16: 687-693.

20. Saito T, Fukai A, Mabuchi A, Ikeda T, Yano F, Ohba S, Nishida N, Akune T, Yoshimura N, Nakagawa T, Nakamura K, Tokunaga K, Chung UI, Kawaguchi H. Transcriptional regulation of endochondral ossification by HIF-2alpha during skeletal growth and osteoarthritis development. Nat Med. 2010; 16: 678-686.

21. Goldring MB, Otero M, Plumb DA, Dragomir C, Favero M, El Hachem K, Hashimoto K, Roach HI, Olivotto E, Borzi RM, Marcu KB. Roles of inflammatory and anabolic cytokines in cartilage metabolism: signals and multiple effectors converge upon MMP-13 regulation in osteoarthritis. Eur Cell Mater. 2011; 21: 202-220.

22. Smith SR, Deshpande BR, Collins JE, Katz JN, Losina E. Comparative pain reduction of oral non-steroidal antiinflammatory drugs and opioids for knee osteoarthritis: systematic analytic review. Osteoarthritis Cartilage. 2016; 24: 962-972.

23. Wang MH, Li LZ, Sun JB, Wu FH, Liang JY. A new antioxidant flavone glycoside from Scutellaria baicalensis Georgi. Nat Prod Res. 2014; 28: 1772-1776.

24. Sun Y, Zhao Y, Wang X, Zhao L, Li W, Ding Y, Kong L, Guo Q, Lu N. Wogonoside prevents colitis-associated colorectal carcinogenesis and colon cancer progression in inflammation-related microenvironment via inhibiting NF-kappaB activation through PI3K/Akt pathway. Oncotarget. 2016; 7: 34300-34315. doi: 10.18632/ oncotarget.8815.

25. $\mathrm{Ku} \mathrm{SK}, \mathrm{Bae}$ JS. Antithrombotic activities of wogonin and wogonoside via inhibiting platelet aggregation. Fitoterapia. 2014; 98: 27-35.

26. Yang YZ, Tang YZ, Liu YH. Wogonoside displays antiinflammatory effects through modulating inflammatory mediator expression using RAW264.7 cells. J Ethnopharmacol. 2013; 148: 271-276.

27. Chen Y, Lu N, Ling Y, Gao Y, Wang L, Sun Y, Qi Q, Feng F, Liu W, Liu W, You Q, Guo Q. Wogonoside inhibits lipopolysaccharide-induced angiogenesis in vitro and in vivo via toll-like receptor 4 signal transduction. Toxicology. 2009; 259: 10-17.

28. Guillemin F, Rat AC, Mazieres B, Pouchot J, Fautrel B, Euller-Ziegler L, Fardellone P, Morvan J, Roux CH, Verrouil E, Saraux A, Coste J, 3000 Osteoarthritis Group. Prevalence of symptomatic hip and knee osteoarthritis: a two-phase population-based survey. Osteoarthritis Cartilage. 2011; 19: 1314-1322.

29. Vinatier C, Merceron C, Guicheux J. Osteoarthritis: from pathogenic mechanisms and recent clinical developments to novel prospective therapeutic options. Drug Discov Today. 2016; 21: 1932-1937. 
30. Nazzal MI, Bashaireh KH, Alomari MA, Nazzal MS, Maayah MF, Mesmar M. Relationship between improvements in physical measures and patient satisfaction in rehabilitation after total knee arthroplasty. Int J Rehabil Res. 2012; 35: 94-101.

31. Tai MC, Tsang SY, Chang LY, Xue H. Therapeutic potential of wogonin: a naturally occurring flavonoid. CNS Drug Rev. 2005; 11: 141-150.

32. Hashimoto S, Takahashi K, Amiel D, Coutts RD, Lotz M. Chondrocyte apoptosis and nitric oxide production during experimentally induced osteoarthritis. Arthritis Rheum. 1998; 41: 1266-1274.

33. Sasaki K, Hattori T, Fujisawa T, Takahashi K, Inoue H, Takigawa M. Nitric oxide mediates interleukin-1-induced gene expression of matrix metalloproteinases and basic fibroblast growth factor in cultured rabbit articular chondrocytes. J Biochem. 1998; 123: 431-439.

34. Koch B, Baum W, Burmester GR, Rohwer P, Reinke M, Zacher J, Kirchner H, Kalden JR. [Prostaglandin $\mathrm{E} 2$, interleukin 1 and gamma interferon production of mononuclear cells of patients with inflammatory and degenerative joint diseases]. [Article in German]. Z Rheumatol. 1989; 48: 194-199.

35. Hardy MM, Seibert K, Manning PT, Currie MG, Woerner BM, Edwards D, Koki A, Tripp CS. Cyclooxygenase 2-dependent prostaglandin E2 modulates cartilage proteoglycan degradation in human osteoarthritis explants. Arthritis Rheum. 2002; 46: 1789-1803.

36. Zheng W, Zhang H, Jin Y, Wang Q, Chen L, Feng Z, Chen $\mathrm{H}, \mathrm{Wu}$ Y. Butein inhibits IL-1beta-induced inflammatory response in human osteoarthritis chondrocytes and slows the progression of osteoarthritis in mice. Int Immunopharmacol. 2017; 42: 1-10.

37. Hamilton JL, Nagao M, Levine BR, Chen D, Olsen BR, Im HJ. Targeting VEGF and its receptors for the treatment of osteoarthritis and associated pain. J Bone Miner Res. 2016; 31: 911-924.

38. Rigoglou S, Papavassiliou AG. The NF-kappaB signalling pathway in osteoarthritis. Int J Biochem Cell Biol. 2013; 45: 2580-2584.

39. Zhang L, Ren Y, Yang C, Guo Y, Zhang X, Hou G, Guo X, Sun N, Liu Y. Wogonoside ameliorates lipopolysaccharideinduced acute lung injury in mice. Inflammation. 2014; 37 : 2006-2012.

40. Martelli AM, Evangelisti C, Chiarini F, McCubrey JA. The phosphatidylinositol 3-kinase/Akt/mTOR signaling network as a therapeutic target in acute myelogenous leukemia patients. Oncotarget. 2010; 1: 89-103. doi: 10.18632/oncotarget.114.

41. Ogita S, Lorusso P. Targeting phosphatidylinositol 3 kinase (PI3K)-Akt beyond rapalogs. Target Oncol. 2011; 6: 103-117.

42. Zeng T, Zhang CL, Song FY, Zhao XL, Yu LH, Zhu ZP, Xie KQ. PI3K/Akt pathway activation was involved in acute ethanol-induced fatty liver in mice. Toxicology. 2012; 296: 56-66.

43. Pessler F, Dai L, Diaz-Torne C, Gomez-Vaquero C, Paessler ME, Zheng DH, Einhorn E, Range U, Scanzello C, Schumacher HR. The synovitis of "non-inflammatory" orthopaedic arthropathies: a quantitative histological and immunohistochemical analysis. Ann Rheum Dis. 2008; 67: 1184-1187.

44. Glasson SS, Blanchet TJ, Morris EA. The surgical destabilization of the medial meniscus (DMM) model of osteoarthritis in the $129 / \mathrm{SvEv}$ mouse. Osteoarthritis Cartilage. 2007; 15: 1061-1069.

45. Wang P, Zhang F, He Q, Wang J, Shiu HT, Shu Y, Tsang WP, Liang S, Zhao K, Wan C. Flavonoid compound icariin activates hypoxia inducible factor-1alpha in chondrocytes and promotes articular cartilage repair. PLoS One. 2016; 11: $\mathrm{e} 0148372$.

46. Au RY, Al-Talib TK, Au AY, Phan PV, Frondoza CG. Avocado soybean unsaponifiables (ASU) suppress TNFalpha, IL-1beta, COX-2, iNOS gene expression, and prostaglandin E2 and nitric oxide production in articular chondrocytes and monocyte/macrophages. Osteoarthritis Cartilage. 2007; 15: 1249-1255.

47. Zhu S, Dai J, Liu H, Cong X, Chen Y, Wu Y, Hu H, Heng BC, Ouyang HW, Zhou Y. Down-regulation of Rac GTPaseactivating protein OCRL1 causes aberrant activation of Rac1 in osteoarthritis development. Arthritis Rheumatol. 2015; 67: 2154-2163.

48. Reagan-Shaw S, Nihal M, Ahmad N. Dose translation from animal to human studies revisited. FASEB J. 2008; 22: 659-661.

49. Glasson SS, Chambers MG, Van Den Berg WB, Little CB. The OARSI histopathology initiative - recommendations for histological assessments of osteoarthritis in the mouse. Osteoarthritis Cartilage. 2010; 18: S17-23.

50. Lewis JS, Hembree WC, Furman BD, Tippets L, Cattel D, Huebner JL, Little D, DeFrate LE, Kraus VB, Guilak F, Olson SA. Acute joint pathology and synovial inflammation is associated with increased intra-articular fracture severity in the mouse knee. Osteoarthritis Cartilage. 2011; 19: 864-873. 